\title{
Economical Surface Balloon Deployment System Concept For Future Scout Class Mars Missions
}

\author{
Nilton O. Renno ${ }^{1}$, Shintaro Taniguchi ${ }^{2}$, Fei Xu ${ }^{3}$, Ryan W. Kurkul ${ }^{4}$, Paul Kuhlman ${ }^{5}$, \\ Elizabeth A. Jones ${ }^{1}$, Shaneen F. Braswell ${ }^{1}$, and Andrew H. Huang ${ }^{4}$ \\ University of Michigan, Ann Arbor, MI, 48109
}

\begin{abstract}
[Abstract] The United States has established a vision for space exploration that includes human missions to the Moon, and eventually to Mars. In order for this vision to turn into reality, the Martian environment must be understood thoroughly to minimize the risk to humans. Although Mars rovers and orbiting satellites are able to gather a significant amount of planetary data, neither platform provides enough information to assess all risks to human exploration, nor do they provide a good balance between mobility and precise, insitu measurements. Fortunately, many of these requirements can be fulfilled with simple balloon missions. This fact has driven the University of Michigan team to invest in the development of the Mars Balloon Scout (MBS) mission. The objectives of the MBS mission include the search for organic compounds and toxic elements in the atmosphere, meteorology and dust electrification measurements, and exploration of the local Mars geology. The balloon system complements landed and orbital missions because of its ability to perform in-situ atmospheric measurements, survey the surface from low altitude, and its relative simplicity and long mission life span when compared to airplanes. However, since the perception of risk is high, balloons or airplanes have not been utilized in a Mars mission yet. The riskiest parts of a Mars balloon mission are the entry, descent, and deployment (EDD) phases. Typical EDD phases of previous missions, such as the Mars Exploration Rovers (MER) mission, lasted approximately six minutes from entry to touchdown, which leaves limited time for balloon deployment and inflation. In the past, most Mars Balloon Mission Concepts have proposed the idea of inflating the balloon during the entry-descent phase. This method eliminates the risk of rupture of the balloon envelope during deployment on the rocky Martian surface. Although balloon inflation during entry-descent was initially believed to be the best method, tests conducted by NASA's Jet Propulsion Laboratory (JPL) and Wallops Flight Facility (WFF) suggests that the technology has not reached the minimum Technology Readiness Level (TRL) required for a flight project yet. Moreover, the number of tests was limited because of the high costs of stratospheric tests. As a result of the low TRL of midair balloon inflation systems and the high costs and risks associated with the technology development, our group at the University of Michigan has been studying a new concept, the balloon inflation at the Martian surface after landing. This idea is more economical when compared to the conventional deployment during descent, and allows the technology to become flight ready faster and at lower cost. Successful implementation of the new surface balloon inflation technology will allow for a low-risk balloon mission, and could ultimately advance NASA's goal of sending humans to Mars.
\end{abstract}

\footnotetext{
${ }^{1}$ Associate Professor, University of Michigan-Ann Arbor, Department of Atmospheric, Oceanic, and Space Science

${ }^{2}$ Student, University of Michigan-Ann Arbor, Department of Atmospheric, Oceanic, and Space Science

${ }^{3}$ Student, University of Michigan-Ann Arbor, Department of Electrical Engineering and Computer Science

${ }^{4}$ Student, University of Michigan-Ann Arbor, Department of Mechanical Engineering

${ }^{5}$ Student, University of Michigan-Ann Arbor, Department of Aerospace Engineering
} 


\subsection{Introduction to Mars Balloon Missions}

The United States has established a vision for space exploration that will lead to human missions to the Moon, and eventually to Mars [1]. In order for this vision to become a reality, the Martian environment must be understood thoroughly to minimize potential risks to the human exploration program. Although Mars rovers and orbiting satellites are able to gather a significant amount of planetary data, neither form of exploration provides adequate information to assess all risks to human exploration, nor do they provide a good balance between mobility and precise in-situ measurements.

Fortunately, many of these requirements can be fulfilled with aerial robotic (aerobot) missions. Amongst the proposed aerobot concepts, the balloon system has various advantages with respect to the airship and airplane because these two are more complex.

The objectives of potential balloon missions to Mars may include the search for organic compounds and toxic elements in the atmosphere, and studies of meteorology, and dust electrification. These science objectives can be achieved by a superpressure balloon system [2], [3], [4], [5], [6]. This balloon concept is noteworthy because of its simplicity, ability to perform in-situ measurements in the Martian atmosphere over large areas, ability to survey the surface, and its relatively long mission life span when compared to airplanes.

A summary of the advantages and disadvantages of various Mars balloon concept options are shown below. The superpressure balloon outranks the other concepts because of its ability to carry out science missions that would contribute significantly to the US vision for human exploration of Mars.

\section{Zero-pressure Balloon Concept [2]}

Advantage

- Good flight heritage from successful operations in Earth's stratosphere above $30 \mathrm{~km} \mathrm{[2].} \mathrm{(At} \mathrm{above} 30 \mathrm{~km}$ on Earth the atmosphere is similar to Mars)
Disadvantage

- Short mission duration (a few days), requires significant amount of ballast to maintain altitude during each day-tonight cycle [2].

- Long mission duration is only possible (30 days) if flown in the polar regions during periods of quasi-constant daylight because of reduced ballast requirements.

Infrared Montgolfier Balloon Concept [2] Disadvantage

- Not possible because the cold Mars surface does not provide adequate infrared flux to keep the balloon aloft at night.

\section{Solar Montgolfier Balloon Concept [2]}

Advantage

- Long mission duration possible.

Disadvantage

- Mission only possible in Polar Regions during solstice when solar energy is available continuously.

Balloon \& Guiderope Hybrid Vehicle Concept [2] Advantage

- Possesses the capability to fly long duration missions other than polarregions.

Disadvantage

- High risk in balloon survivability.

- Challenges in mitigating risk items.

Superpressure Balloon Concept [2], [3], [4], [5] Advantage

- Long mission duration possible

- Missions possible in Most Martian regions

- Good flight heritage from operations in Earth's stratosphere such as GOST and STRATEOLE. Flight record of 744 days in GHOST.

- Various balloon designs available for mission duration optimization. Spherical, Pumpkin Shape Balloon Design (Ultra Long Duration Balloon)

\section{Disadvantage}

- Maintains constant altitude during flight which reduces the possibility of scientific measurements at various altitudes. 


\subsection{Challenges of Mars Balloon Missions}

Aerial robotic explorers including balloon systems have not been utilized in a Mars mission yet. Consequently, the perception of risk is high and this has contributed to the selection of rovers and orbiters over balloons in recent mission proposal cycles. The technological risk is also high in conventional aerial balloon deployment strategies [2], [3], [4], [5], [6] because the balloon is inflated during the short entry, descent, and deployment (EDD) phase.

The entry, descent, and deployment/landing phase is considered to be one of the riskiest phases of any Mars mission that requires atmospheric entry. Typical EDD phases of previous missions, such as the Mars Exploration Rovers (MER) mission, lasted approximately six minutes [7] from entry to touchdown limiting the balloon inflation time to approximately a maximum of 2-3 minutes [2]. The short time and high descent velocities (From $430 \mathrm{~m} / \mathrm{s}$ to 85 $\mathrm{m} / \mathrm{s}$ ) [7] that would be encountered during balloon inflation requires an extremely high gas flow rate from the tank to the balloon and increases the already high aerodynamic loadings on the balloon envelope [5].

The challenges to this type of deployment is that the balloon material needs to be light enough for it to float but strong enough to overcome the stress load requirements [2]. Thus, advancement in Nano film technology that is not mature yet might be necessary for this type of mission. Moreover, the conventional aerial deployment strategy faces a dilemma because it is difficult to accurately model and collect deployment data with simple tests. The maturation of the technology for balloon inflation requires a large number of deployment tests because numerical models of complex aeroelastic problems are not currently available. The high cost of stratospheric deployment tests limits our ability to conduct the many tests necessary for advancing the technology.

In the past ten years, conventional aerial balloon deployment technology has been making slow progress because of the small funding allocated for it. The superpressure balloon is a promising technology for future missions but the current balloon inflation strategy does not meet the minimum Technology Readiness Level (TRL) required for a flight project. This has driven our group at the University of Michigan to investigate balloon deployment strategies that could be economically tested.

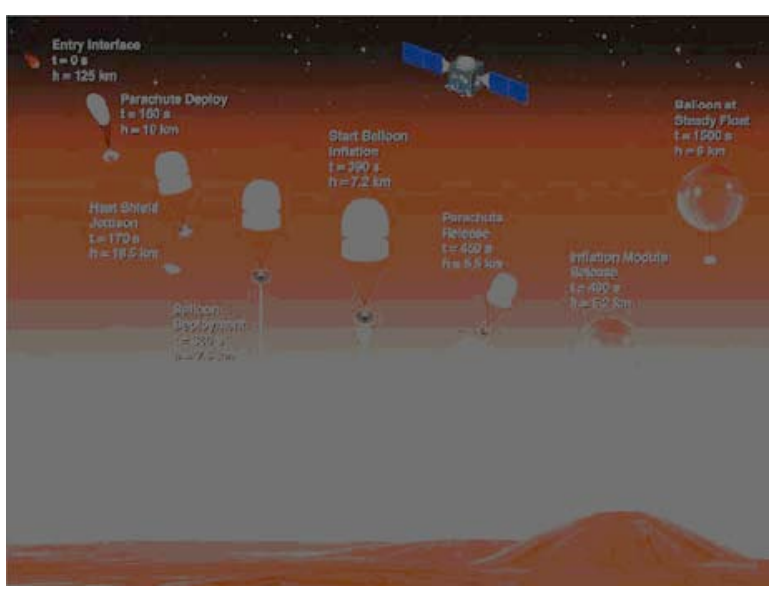

Figure 2-1: Conventional Aerial Balloon Deployment Strategy Sequence [2].

1) Entry Interface

2) Parachute Deploy

3) Heat Shield Jettison

4) Balloon Deployment

5) Start of the Balloon Inflation

6) Parachute Release

7) Inflation Module Release

8) Balloon Floating Steadily

\subsection{Balloon Inflation at the Ground}

The maturation of conventional balloon aerial deployment strategy requires a complex test matrix that requires a large number of tests in the Earth's stratosphere [2], [3], [4]. The deployment tests must be conducted in the Earth's stratosphere because it has properties similar to the Martian atmosphere. In the conventional deployment strategy, the majority of the funds available for technology maturation have been invested in these complex stratospheric deployment tests. Thus, in order to reduce costs it would ideal if tests could be conducted on the ground within existing NASA, industry, and University facilities. Based on these ideas, a new concept 
was developed by the University of Michigan researchers. In this new concept, inflation of the balloon occurs at the surface of Mars (ground) after the Entry, Descent, and Landing (EDL) phase. Thus, the time for the balloon to inflate is independent of the EDL phase, because the balloon does not have to inflate and float before the decent capsule reaches the ground. This reduces the balloon envelope stress requirements, allowing existing film technology, such as polyester (Mylar ${ }^{\text {TM }}$ ) and Polyethylene to be used for the balloon envelope. This new balloon deployment concept can also simplify the inflation tests. Moreover, in this case all inflation tests can be done on Earth's ground and therefore the costly stratospheric tests are eliminated. The majority of the tests can be done in wind tunnels and vacuum chambers in existing NASA, industry, and University facilities. This dramatically reduces the cost for each critical test and therefore a larger number of tests can be done to quickly mature the technology.

The following criteria are risk items and reasoning that describe why surface balloon inflation was not considered previously:

- On Earth, scientific balloons are inflated and launched from the ground by several people. Absolutely no humanassistance is available on Mars [2].

- Aerodynamic forces due to wind may make the balloon contact the rocky Martian surface, resulting in the rupture of the balloon envelope [2].

- Currently, the autonomous balloon launch technology concept is not available yet [2].

- The two Soviet Venus VEGA balloons [8] were the first and only planetary balloon missions. Thus, only conventional balloon deployment strategies have flight heritage [2], [4].

However, the balloon ground inflation concept must still be considered because of the relatively low cost necessary to mature this technology. Our reasoning is that the VEGA balloon deployment strategy [8] has flight heritage, but it was designed for Venus and because Mars has a much less dense atmosphere it is harder to deplot and make a balloon to float there. Thus, flight heritage on Venus does not translate into heritage for Mars. The surface balloon inflation technique may allow the development of a lowcost aerobot mission to Mars. The sequence of events of the surface balloon deployment strategy is shown below in Figure 3-1.

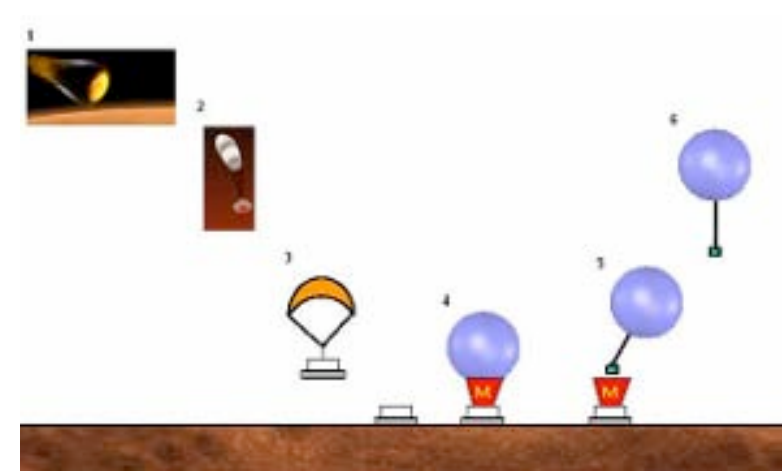

Figure 3-1: New Proposed Surface Balloon Deployment Strategy Sequence

1) Atmospheric Entry

2) Parachute Deployment

3) Heat Shield Jettison, Parachute Descent \& Landing

4) Balloon Deployment

5) Balloon Release

6) Balloon Floating Phase

\subsection{Surface Inflation Concept}

Studies by both JPL and NASA Wallops have shown that a long duration balloon flight on Mars is possible as long as the balloon can be properly inflated [2]. Achieving this inflated state has proved to be difficult [2], [3], [4], [5]. When high altitude balloons are launched on Earth, people are present to handle the balloons and prevent them from possibly tearing on the ground. Inflation on the Martian surface would have similar challenges, including typical surface winds ranging from 0 to $10 \mathrm{~m} / \mathrm{s}$ [9],[10], which could push an under-inflated balloon sideways and force it to contact the rocky surface, or cause strong stresses that could tear the balloon envelope.

The goal of a ground-based Mars balloon launcher is to protect the balloon from 
these dangers while it is initially being inflated, so that the balloon has enough time to fully inflate and rise to a safe altitude. A groundbased balloon deployment system must be designed for a number of possible landing environments, because the precision of landings on Mars is limited [6]. Thus, there is no costeffective way to accurately predict the local environment that the balloon will be required to inflate in. Given these uncertainties, it is safer to make a passive system for protecting the balloon, as opposed to an active one. This is why we chose to develop a passive guidance funnel which is deployed out of the Mars lander in order to protect the balloon during inflation at the ground.

\subsection{Surface Inflation System Concepts}

We considered four initial system design concepts for ground inflation. The first concept was the use of a small pilot balloon to lift the top of the large balloon during inflation. This pilot balloon would provide buoyancy that would keep the partially inflated large balloon from touching the ground. Our analysis showed that the pilot balloon's radius would have to be more than $60 \%$ of that of the large balloon in order to provide sufficient buoyancy to guarantee safe inflation based on $20 \mathrm{~m}$ diameter balloon with envelope material surface density of $10 \mathrm{~g} / \mathrm{m}^{2}$. Problems with this design were that we would face the same obstacles inflating the pilot balloon as inflating the main balloon. There was also the problem of routing lifting gas such helium and hydrogen to the small balloon with a tube, and the reliability tests of this system. Calculations of various parameters of this concept can be seen in Appendix A.

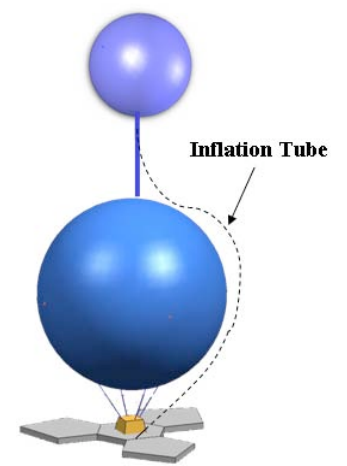

Figure 4-1: Small Balloon Concept
The second design concept consisted of a large pad deployed around the lander. This pad would cushion the balloon if it ever came in contact with the ground, preventing the balloon from tearing. One of our concerns with this design was whether or not the pad would puncture or tear on the Martian surface during deployment. Testability was also an issue with this design because mimicking all possible situations on the Martian surface could be difficult.

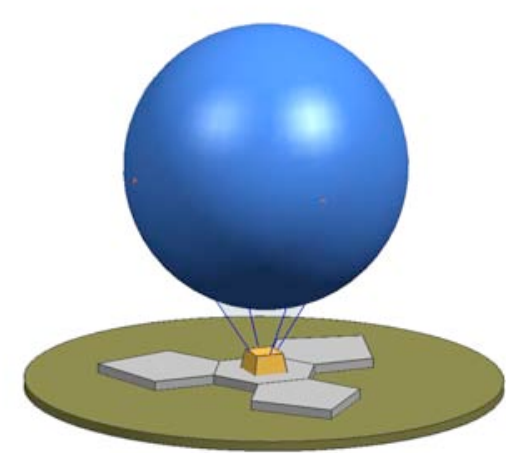

Figure 4-2: Large Pad Concept

We also considered using electrostatic forces to keep the balloon above the ground and within the lander structure. But charge generation methods, such as Van de Graaff Generators, are extremely high mass. In addition, electrostatic conditions on Mars are not well understood, which could possibly make control of the balloon charges difficult. This method could also effect the science instrument measurements which will affect the science and engineering instrument requirements making it a not ideal design.

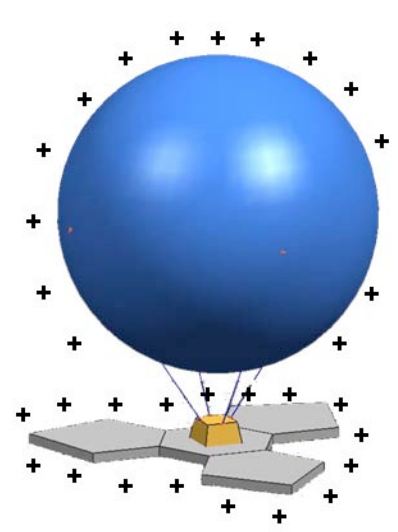

Figure 4-3: Electrostatic Concept 
Our last design concept consisted of a funnel connected to the lander. The funnel concept would guide the balloon upward as it is inflated, and the balloon would exit at the top of the funnel. The funnel height would be such as to guarantee that the balloon would not touch the ground. The funnel could be either a free standing or an inflatable / deployable structure.

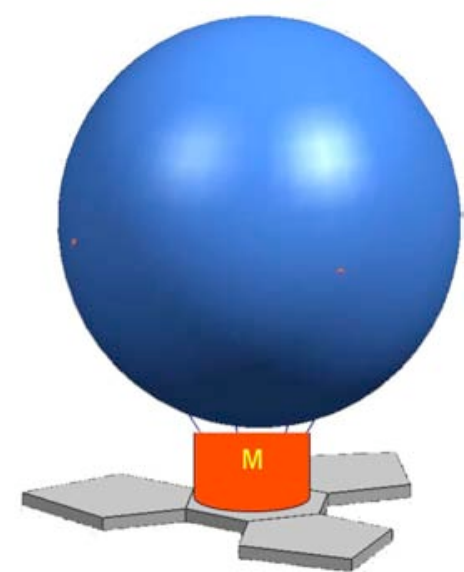

Figure 4-3: Funnel Concept

\subsection{Design Selection}

The funnel design was chosen for its testability and low cost. We could test several different funnel designs and deployment strategies quickly and at low cost. The small balloon design was discarded because inflating it was as difficult as inflating the large balloon. The large pad idea was nearly impossible to test because of difficulties recreating the Martian surface on Earth. The electrostatic idea was too complex and heavy. Moreover, both the balloon and the lander could be charged by natural processes on Mars, making the control of their charges difficult.

\subsection{Funnel Design Selection}

Several different funnel geometries and materials were considered. We selected a cylindrical shaped funnel because it has lower surface area than a conical funnel of the same height, thus lowering mass while providing similar stability properties. We considered both an inflatable funnel and a metallic/plastic funnel. The advantages of using an inflatable funnel are that it could be packed into a small space, leaving room for other hardware in the landing module. It can also be easily constructed and tested. The metallic/plastic funnel would be heavier and take up more space than the inflatable funnel. But if it could be constructed using several spring-loaded components, then the funnel could be light enough and small enough to be an option. With the simple information system that we propose, the inflatable cylindrical funnel is the best option, but other funnel option should still be examined.

\subsection{Scaling Analysis}

\subsection{Scaling Motivation}

Upon the selection of the ground-launch system concept, the funnel concept, for the Mars balloon mission, we were confronted with the task of validating the system that would work best on Mars. Experimental testing of the ground-launch must be conducted to assure that the new system will work at the surface of Mars. All mechanical elements of the deployment system where failure might occur must be studied analytically, computationally or experimentally.

We focused our attention on the item of largest concern in our design concept for the validation of the ground-lunch system. This item is the possibility of envelope rupture due to wind loading as the balloon is launched from the Martian surface. The complex wind-balloon interaction is not currently well understood by either analytical or computational methods; thus, our study was reduced to the classic method of aerospace engineering: scaling and model testing.

At the early stage of the concept validation, we employed only tests that could be conducted outdoors economically. Thus, scaling analysis played an important role in the prototype development and test. However, the challenge of ensuring that our scale models behaved the same way on Earth as the final product would behave on Mars is difficult but not impossible ${ }^{1}$.

This is believed to be true, according to the 
Central to ensuring this similarity is the adoption or conception of an appropriate set of dimensionless numbers which can be matched between the planned Mars-design and our earthmodel.

\subsection{Dimensionless Numbers}

There are few procedural guidelines to follow when creating an appropriate set of dimensionless numbers, but the principle is simple, and there are several well-established dimensionless numbers to start with such as the Reynolds and the Froude numbers. These numbers capture the ratio of buoyancy and viscous forces, respectively, to aerodynamic forces. The forces themselves cannot be the same between full-size and scale models, but if the dimensionless numbers are matched, then the relationships between the forces are guaranteed to be the same. Thus if all of the system's relevant physical variables are included in a completely interconnected web of such relationships, dynamical similarity is achieved. Table 5.1 and 5.2 contain the relevant physical parameters $(\mathrm{M}=$ mass, $\mathrm{L}=$ length, \& $\mathrm{T}=$ time).

\begin{tabular}{lcc}
\hline Variable Name & Symbol & Units \\
\hline Atmospheric Density & $\rho$ & $\mathrm{ML}^{-3}$ \\
Gravitational Acceleration & $\mathrm{g}$ & $\mathrm{LT}^{-2}$ \\
Wind Viscosity & $\mu$ & $\mathrm{ML}^{-1} \mathrm{~T}^{-1}$ \\
\hline
\end{tabular}

Table 5-1: Variables with Known Values

\begin{tabular}{|c|c|c|}
\hline Variable Name & Symbol & Units \\
\hline Wind Velocity & $\mathrm{V}$ & $\mathrm{LT}^{-1}$ \\
\hline Balloon Diameter & $\mathrm{D}$ & $\mathrm{L}$ \\
\hline $\begin{array}{l}\text { Displacement Density } \\
(\rho-\rho \text { inside envelope })\end{array}$ & $\Delta \rho$ & $\mathrm{ML}^{-3}$ \\
\hline Envelope Surface Density & $\rho_{\mathrm{s}}$ & $\mathrm{ML}^{-2}$ \\
\hline Envelope Surface Strength & $\mathrm{T}$ & $\mathrm{MT}^{-2}$ \\
\hline Envelope Surface Stiffness ${ }^{2}$ & $E \cdot t^{3}$ & $\mathrm{ML}^{2} \mathrm{~T}^{-2}$ \\
\hline
\end{tabular}

Table 5-2: Variables with Modifiable Values

Buckingham pi theorem, so long as the number of important uncontrollable variables is matched or exceeded by the number of fundamental units making up the important variables. It is not true if our list of uncontrollable variables is lacking, or if any variable we call "controllable" is misnamed.
Nine physical variables were chosen to characterize the system dynamics. These variables contain three fundamental units (mass, length, and time). The Buckingham Pi-Theorem states that the difference between the number of relevant physical parameters and the number of primary quantities used to describe them is equal to the number of dimensionless parameters necessary to describe the system. As a result, a set of six dimensionless parameters is necessary in order to achieve dynamic similarity.

\subsubsection{Reynolds Number}

The Reynolds Number captures the ratio between aerodynamic and viscous forces. It is given by equation 5.1 below.

$$
\operatorname{Re}=\frac{v \cdot \rho \cdot D}{\mu}(\text { Eq. 5.1) }
$$

\subsubsection{Froude Number}

The Froude Number captures the ratio between aerodynamic and buoyancy forces. It is given by equation 5.2 below.

$$
F r=\frac{\rho \cdot v^{2}}{\Delta \rho \cdot g \cdot D}(\text { Eq. 5.2) }
$$

\subsubsection{Aero-Kinetic Parameter}

The Aero-kinetic Parameter was invented by the Mars Balloon team. It is intended to capture the relationship between the movement of fluid vortices created by the wind passing over the balloon envelope and the movement of the envelope surface itself which is forced by these vortices. It is given by equation 5.3.

2 Envelope surface stiffness, as an important variable, was introduced later in the design and construction process, as it became evident that the envelope material's ability to "fold nicely" plays an important role in the balloon's deployment, and perhaps also its dynamic behavior in the partially-deployed stage. Its value is taken to be equal to the envelope material's elastic modulus multiplied by envelope thickness to the third power, which is derived from beam theory, and intended to represent the envelope's resistance to increasing angle of folding. 


$$
A k=\frac{\rho \cdot D}{\rho_{s}} \quad(\text { Eq. 5.3) }
$$

We believe that this relationship is important because it determines the character of periodic ripples across the surface of the balloon.

The Aero-kinetic Parameter is derived by finding the characteristic acceleration of a differential balloon surface element, which is equal to dynamic pressure force divided by surface element mass, and comparing this acceleration to the expected acceleration of lowpressure turbulent vortices traveling over the balloon's surface (taken as proportional to $\mathrm{V}^{2} / \mathrm{D}$ ). This acceleration, captured by the Stroul Number, has been shown by Von Karman to be nearly a function of the Reynolds number alone, which we already include in the list of important parameters. Some further explanation of the number is presented in Appendix B-1.

\subsubsection{Buoyancy Parameter}

We created the Buoyancy Parameter to capture the ratio of buoyant force to envelope weight. The buoyancy parameter is given by equation 5.4 below.

$$
B u=\frac{\Delta \rho \cdot D}{\rho_{s}} \quad \text { (Eq. 5.4) }
$$

\subsubsection{Envelope Strength Parameter}

We created the Envelope Strength Parameter to capture the ratio of aerodynamic stress on the envelope to the stress that it is capable of withstanding. This parameter ensures that if our balloon remains unbroken from wind forces during testing, it will remain unbroken when deployed on mars. It is given by equation 5.5 below.

$$
\mathrm{T} s=\frac{\rho \cdot v^{2} \cdot D}{\tau}(\text { Eq. 7.5) }
$$

\subsubsection{Envelope Stiffness Parameter}

The Envelope Stiffness Parameter is intended to capture the ratio of the aerodynamic force pushing on the balloon surface to the force with which the surface pushes back. It was derived from beam theory and added to the set later in the project's development when its importance became evident. Its derivation is described in Appendix B-2. It is given by equation 5.6.

$$
S u=\frac{E \cdot t^{3}}{D^{3} \cdot \rho \cdot v^{2}}(\text { Eq. 5.6) }
$$

\subsubsection{Results of the Non-dimensional Analysis}

The non-dimensional analysis is intended to inform us to which values the controllable variables should be set so that the scale modeling will be accurate. For solving these six unknowns we have an equal number of equations, formed from our six dimensionless numbers. On one side of each equation are the values for the mars-design, and on the other are the variables for the earth-model. The equations are rewritten in terms of ratios, and solved simultaneously to give us the scaling ratios for our experiments. The ratio values used for our analysis are shown below in Table 5-3 below. The detail calculations of how these ratio values were derived can be seen in Appendix C.

\begin{tabular}{ll}
\hline $\mathrm{D} \sim 0.05$ & balloon diameter ratio \\
$\Delta \rho \sim 80$ & (outer-inner density) ratio \\
$\mathrm{p}_{\mathrm{s}} \sim 4.00$ & envelope surface density ratio \\
$\tau \sim 0.55$ & envelope surface strength ratio \\
$\mathrm{v} \sim 0.37$ & wind velocity ratio \\
\hline
\end{tabular}

Table 5-3: Ratio of experimental variables between Earth and Mars Balloons

\section{Balloon Diameter Ratio}

Since D 0.05, the diameter of the Earth balloon must be about 5 percent of the Mars balloon. Thus, a $20 \mathrm{~m}$ diameter Mars balloon is dynamically similar to an Earth balloon with a diameter of approximately 1 meter.

\section{Balloon (Outer-Inner Density) Ratio}

The difference in gas density outside and inside the balloon must be 80 times greater on Earth than on Mars, which is valid as atmospheric density difference between Earth and Mars is closed to 80 times.

\section{Balloon Envelope Surface Density Ratio}

The balloon material in our experiments must be also about 4 times heavier per unit surface area than the Mars balloon material. Based on Mars 
balloon envelope surface area density of 10 $\mathrm{g} / \mathrm{m}^{2}$, the Earth balloon surface density would need to be approximately $40 \mathrm{~g} / \mathrm{m}^{2}$.

\section{Balloon Envelope Surface Strength Ratio}

The balloon material for our terrestrial experiments must be half as strong $(\tau \sim 0.55)$ as the material for the Mars balloon. We assumed that the Mars balloon was made of $10 \mu \mathrm{m}$ Mylar or a similar material, having a tensile strength of $13.8 \mathrm{lb} / \mathrm{in}$. In this case, the FEP film's strength is $3.8 \mathrm{lbs} / \mathrm{in}$. Thus, the FEP is 3.6 times weaker than $10 \mu \mathrm{m}$ Mylar, and this corresponds to a safety factor of 1.8 accordingly.

\section{Wind Velocity Ratio}

Our dimensional analysis suggests that the wind speed on Earth tests must be about 3 times slower than those expected on Mars. The wind speed near the surface of Mars is predicted to be between 0 and $10 \mathrm{~m} / \mathrm{s}$ based on the Mars Pathfinder Mission (MPF) measurements [9], [10]. This means that the wind speed must be between 0 and $3.7 \mathrm{~m} / \mathrm{s}$ on Earth to simulate the Mars deployment condition. Successful deployment of the balloon at wind speed exceeding $3.7 \mathrm{~m} / \mathrm{s}$ on Earth would validate our surface balloon inflation system.

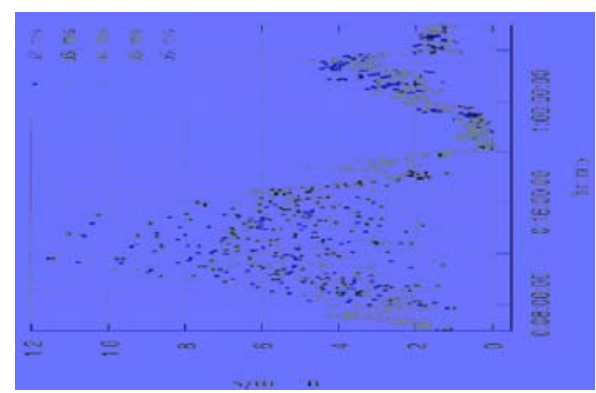

5-1: Surface Wind Measurements from 1996 Mars Pathfinder Mission [9], [10].

\subsection{Design Details of the Funnel Concept}

\subsection{Functional Requirements}

The funnel must keep the balloon from contacting the ground during the early inflation stages. During this stage, the balloon does not contain enough lifting gas such as helium or hydrogen to be positively buoyant, and runs the risk of contacting the ground, which may be very harmful. The funnel must be stable enough to keep the balloon contained and the lander upright when subject to lateral wind-drag forces.

\subsection{Height Requirement}

The funnel's minimum height is determined by the amount of slack that can develop in the balloon as it inflates. The risk of negatively buoyant slack material blowing over the side of the funnel and contacting the ground is a serious concern, thus the funnel must be tall enough to accommodate the maximum possible amount of slack before the top section of the balloon becomes buoyant. Our first order analysis of the minimum funnel height assumes that the helium goes to the top of the balloon immediately, filling a spherical volume at the top of the balloon, while the un-inflated balloon material is deployed through the cylinder. The volume of the small sphere dictates the buoyant force on the top of the balloon, and the length of slack material determines the downward force on the top of the balloon. Calculations in Appendix D-1 show that the funnel must be at least $4.4 \mathrm{~m}$ tall for this condition to be achieved.

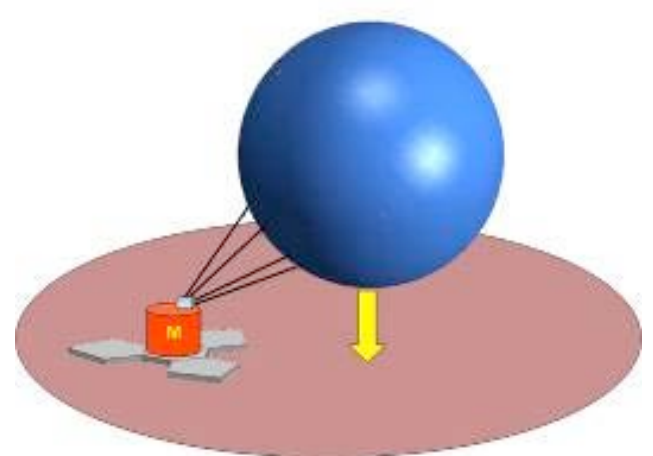

Figure 6-1: Balloon Touching the Ground

Another requirement on the minimum height of the funnel is the behavior of the gondola after initial balloon liftoff. The gondola will be stored outside the perimeter of the funnel, thus if the balloon lifts the gondola off the ground at an angle, the gondola will tend to swing toward the balloon, and toward the ground. This introduces the risk of the gondola being dragged along the ground and hitting an obstacle, such as a large rock. This is avoided by making the funnel tall enough so that the angle of the tether with respect to the ground plane at liftoff is close to 
$90^{\circ}$, even in the presence of typical Martian surface wind velocity of $5 \mathrm{~m} / \mathrm{s}$. Our first order calculations in Appendix D-2 show that the minimum required funnel height to achieve this on Mars based on system with tether length that is 4.5 times the diameter of the balloon is $6.2 \mathrm{~m}$ which translates to a $31 \mathrm{~cm}$ tall funnel using our scale model of balloon diameter ratio shown in section 5.2.7. Additional explanation on our scaling method for the height of funnel can be also found in section 7.3. We also assumed that timing of gondola being released would be controlled in actual mission operation so wind of speed of $5 \mathrm{~m} / \mathrm{s}$ or less can be achieved. In our preliminary analysis, we determined that risk of the gondola being dragged along the ground to be the limiting condition on the minimum size of the funnel.

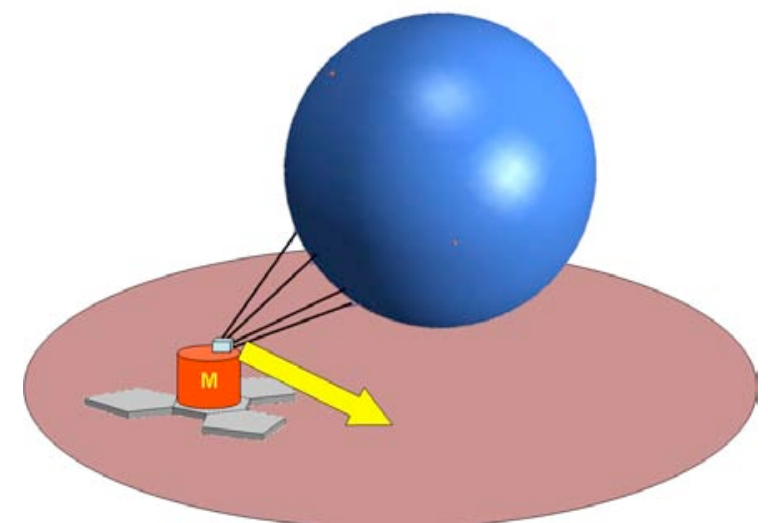

Figure 6-2: Gondola Hitting the Ground

In addition, maximum allowable height of the funnel is determined by the risk of wind drag tipping the lander. This, however will depend on the weight of lander and the position of its center of gravity (CG). Lander design including mass and shape would significantly vary from mission to mission and this analysis must be carried out during the mission design stage.

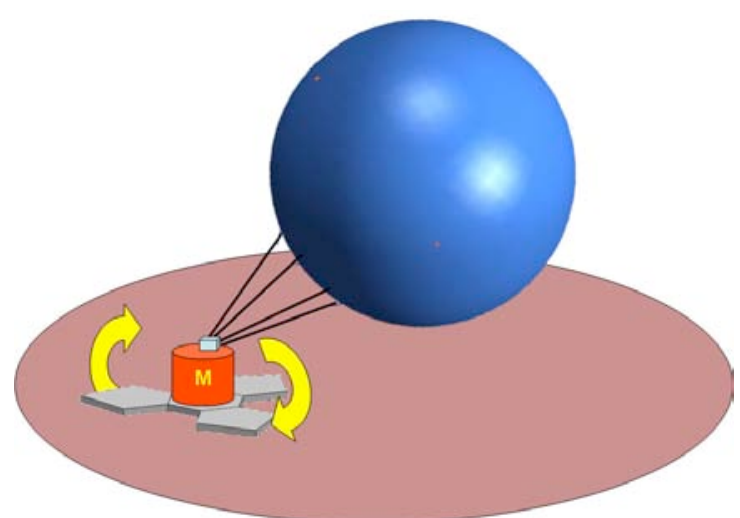

Figure 6-3: Tipping the Lander

\subsection{Construction Methods}

The inflatable funnel is made from a thin plastic film. In our prototype, polyethylene film was used. The Funnel can be folded for packing, but stands upright when inflated.

\subsection{Balloon Packing}

The balloon must be packed into the funnel for deployment at the surface of Mars. However, the packing scheme must be optimized to satisfy space and functionality requirements. The balloon must not be packed in such a way that it restricts airflow to the top of the balloon, since the funnel design capitalizes on helium flowing to the top of the funnel for its effectiveness. The balloon must also be packed into the limited space allotted for the funnel/balloon package aboard the Mars lander. These requirements are mutually exclusive, and a compromise must be found. Early experimental results suggest that a spiral or helical, packing scheme allows compact packing and good airflow from the bottom to the top of the balloon. The spiral may be lowprofile and wide, or tall and thin, depending on the needs of the application or mission. Other packing schemes which involve folding can have smaller volumes, but they severely restrict the airflow to the top of the balloon, and limit the functionality of the system. However, more experiments must be performed in order to an optimum balloon packing strategy to be developed. 


\subsection{Economical Prototype Development \& Testing (Concept Demonstration)}

\subsection{Polyethylene Balloon Prototype}

Our main prototypes were constructed from polyethylene. The material is tough, can be compacted to fit inside the funnel, and it is easy to work with. Our scaling analysis shown in 5.2.7 dictated that the prototypes must have surface area density of about $40 \mathrm{~g} / \mathrm{m}^{2}$. The Polyethylene that we used had a surface area density of approximately $41 \mathrm{~g} / \mathrm{m}^{2}$.

To construct the balloons, sixteen gores were first cut out from large polyethylene sheets. The gores were then fused into each other one by one until the balloon was completed. A small hole was cut on the bottom, and a small valve was installed. Heat shrink wrap was used to make an air tight seal. A scaled gondola was also attached to the balloon bottom.

\subsection{Fluorinated Ethylene Propylene (FEP) Balloon Prototype}

One FEP balloon was constructed. FEP was selected because it matched the scaled strength per unit area of the Mars Balloon. Again, a small hole was cut on the bottom, and a small valve was installed. Heat shrink wrap was used to make the seal around the valve air tight. However, the final product was fragile and could not be packed into the scaled funnel.

\subsection{Cylindrical Funnel Prototype}

The cylindrical funnel prototype was constructed from the polyethylene. Our preliminary scaling analysis of balloon diameter shown in 5.2.7 was used to determine the height of the prototype funnel. The scaling ratio of the Earth balloon diameter compared to the Mars balloon diameter is approximately $5 \%$. Similarly, we will apply a same ratio to our funnel scaling. Since height requirements for the funnel on Mars was $6.2 \mathrm{~m}$, the $5 \%$ of that value would be $31 \mathrm{~cm}$. Thus, 31 $\mathrm{cm}$ is our theoretical height that funnel prototype on Earth needs to demonstrate its ability to deployment the balloon for the outdoor ground test. For our initial prototyping phase, we developed $30 \mathrm{~cm}$ tall funnel.

\subsection{Testing}

We performed open-air experiments in order to test the balloon deployment system's performance. As mentioned above, in order to accurately model the system behavior in winds in excess of $10 \mathrm{~m} / \mathrm{s}$ on Mars, it was necessary to test it in winds in excess of $3.7 \mathrm{~m} / \mathrm{s}$ on Earth.

\subsubsection{Test Conditions}

The tests were performed in an open, flat field, in wind speeds that ranged from 0 to $9 \mathrm{~m} / \mathrm{s}$ on Earth.

\subsubsection{Balloon Deployment System Test}

The balloon deployment was tested in $6.5 \mathrm{~m} / \mathrm{s}$ winds. The stability of the base/funnel/balloon structure was tested in the presence of wind stronger than predicted on Mars, and the ability of the balloon to fully inflate without contacting the ground was also tested. The balloon was made of double-layered polyethylene, and had the mass per unit surface area suggested by the non-dimensional analysis

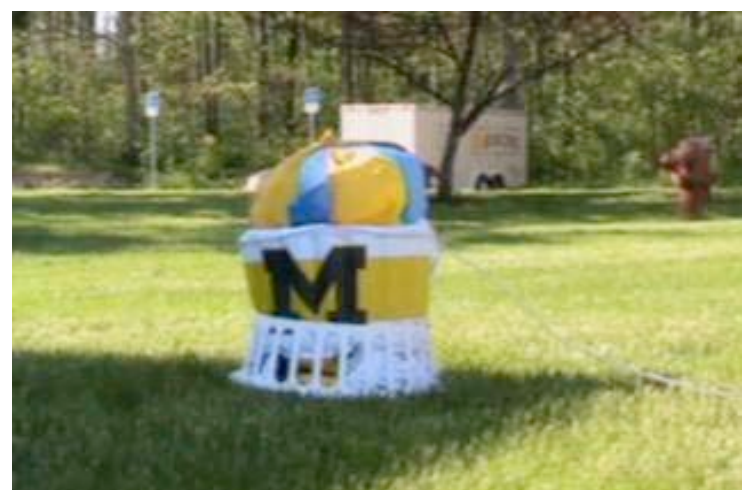

Figure 7-1: Polyethylene Balloon Inflating in $6.5 \mathrm{~m} / \mathrm{s}$

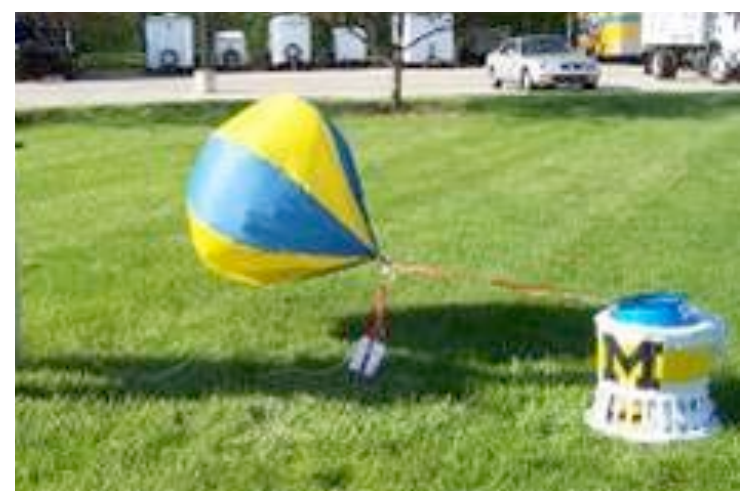

Figure 7-2: Polyethylene Balloon Launching 


\subsubsection{Balloon Deployment System Test}

The system was stable in winds of up to $6.5 \mathrm{~m} / \mathrm{s}$ on Earth, even with the lateral wind drag of a fully inflated balloon, and the balloon was able to inflate and support its own weight without contacting the ground. This means that the balloon would be able to fully inflate without touching the ground on Mars, and that the drag force on the balloon would not disturb the Mars lander.

\subsubsection{FEP Balloon Test}

The FEP balloon was tested to determine if wind-induced stresses would tear the balloon. The FEP material matched the strength needed to reproduce the balloon behavior expected on Mars. The balloon was inflated with helium and allowed the blow in the wind, while held at the base. In a second test, the balloon was held and moved at a fixed speed of $4.5 \mathrm{~m} / \mathrm{s}$. Both tests simulated wind force on the balloon, causing rippling behavior and local stresses to develop across the envelope.

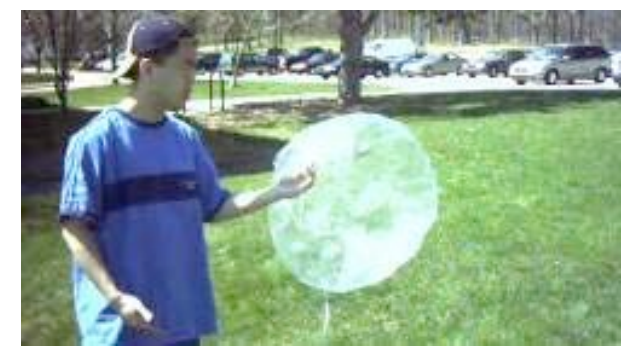

Figure 7-3: Stationary test of FEP Balloon

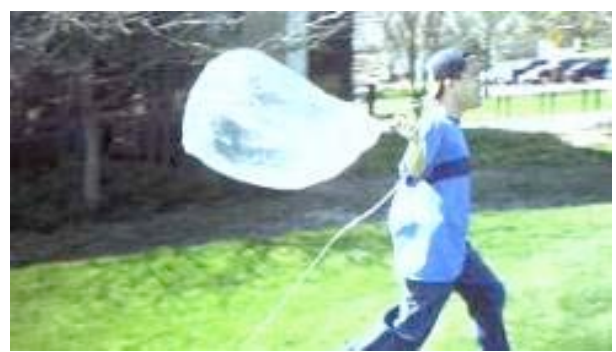

Figure 7-4: Moving test of FEP Balloon

\subsubsection{FEP Balloon Test}

The FEP balloon was checked for tears after the tests. The FEP material exhibited no local stretching or tearing. This means that the balloon would be intact after blowing in the wind during the initial inflation process on Mars. However, additional tests are necessary.

\subsection{Future Tests}

This section details additional experiments and research that should be performed in the future, in order to mature the technology and increase the TRL for the ground-based balloon launch concept.

\subsubsection{Funnel Type}

The shape of the funnel, the material that it is made of, and the manner in which it is deployed all require further investigations. We found that a cylinder was the most effective shape, as it was a compromise between having high stability with an upward facing cone and low friction and abrasion with the balloon on downward facing cone. However, a rigorous analysis of the funnel shape and its impact on balloon deployment is necessary to optimize the deployment system.

Further analysis is also required to determine if the cone should be inflated or be a free-standing deployable mechanical structure. An inflated cone would necessitate additional on-board gas for its inflation. A free standing structure made of plastic or metal may be heavier, but it could be constructed into a geodesic structure to minimize volume and weight. Deploying the free standing structure is an untested discipline, and requires further experimentation.

\subsubsection{Balloon Packing/Folding}

How the balloon is packed within the funnel must also be investigated further. A spiral shape has produced the best results in our tests because it does not restrict airflow to the top of the balloon as much as other packing schemes involving sharp folds in the balloon material. However, the spiral packing scheme is not the most space-efficient packing method. Further experimentation and analysis is necessary in order to determine the optimal packing scheme. 


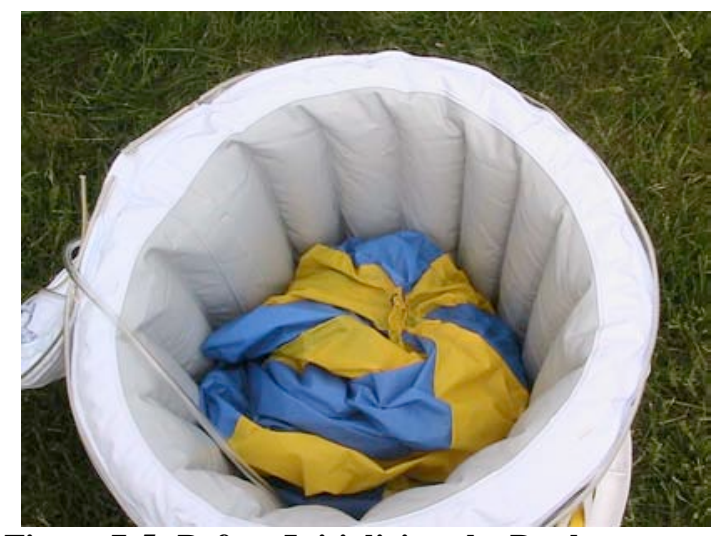

Figure 7-5: Before Initializing the Deployment of the Prototype Balloon

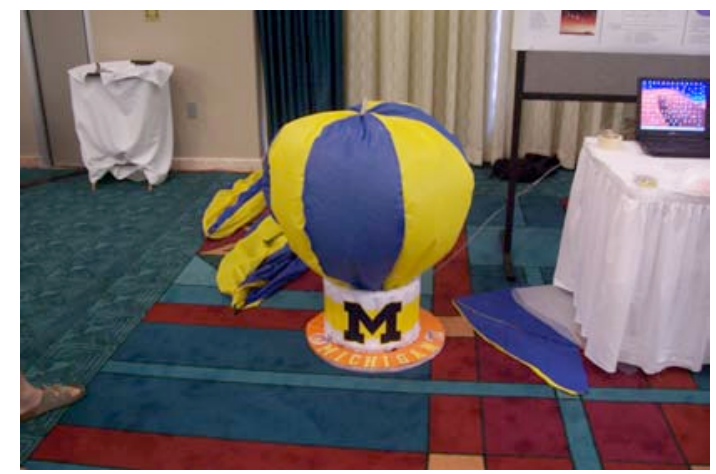

Figure 7-6: During the Deployment of the Prototype Balloon

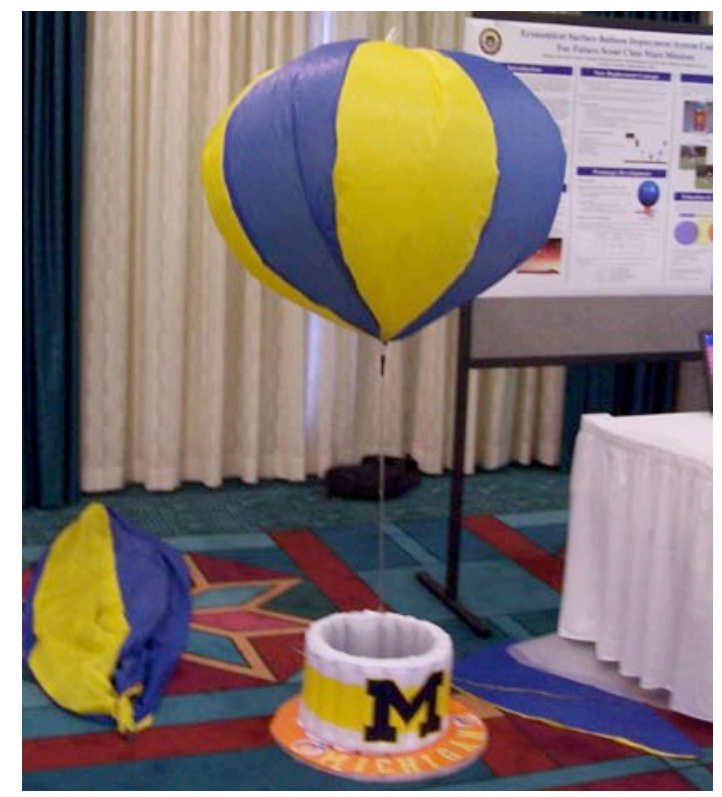

Figure 7-7: After the Deployment of the Prototype Balloon Completed

\subsection{Technology Development Plan to Improve the Technology Readiness Level (Schedule \& Budget: Year 2007 - 2016 \& Beyond)}

The current Technology Readiness Level (TRL) of the proposed balloon surface deployment strategy is between TRL 1-2. Thus, the new balloon inflation system concept must undergo extensive tests to achieve the Technical Readiness Level required for a Mars mission (TRL 7). Based on ground tests to simulate the Martian environmental conditions, the following test will be required. The practicability of our surface balloon inflation will be analyzed and demonstrated through a systems engineering approach (Phase A - Phase D).

\subsection{Development Schedule}

\subsubsection{Phase A: Feasibility Analysis}

The feasibility of our surface balloon inflation technology concept will be developed and evaluated in this phase. Preliminary tests will be done to explore this configuration option on a small scale in the laboratory, wind tunnel, vacuum chamber, and out-door ground test. The goal for Phase A is to develop the basic principles, formulate the technology concepts and their applications, and prove the concepts through analytical and experimental studies (TRL 1 - TRL 3).

\subsubsection{Phase B: Feasibility Demonstration}

\section{Stage One}

In the first stage of Phase B wind tunnel tests, vacuum chamber tests, and ground tests of the sub-scale and full-scale system will be performed. The results from this stage will be used to evaluate the viability of the design. The tests conducted during this stage include inflation in static setting, inflation in dynamic setting (wind gusts), as well as investigations of what environmental factors may affect the balloon inflation process. The goal of 'Stage One' is to validate the concept in the laboratory and field environment (TRL 4 - TRL 5). 


\section{Stage Two}

In the second stage of Phase B, a full-scale system will be tested. Full-scale system will tested in an environment containing parameters similar to the Martian conditions. In addition, eighteen months of storage tests should be conducted to ensure that the fabric used for the inflatable funnel will be able to maintain functionality after the eighth-month of interplanetary cruise. This stage will determine the feasibility of the design at the full-scale system (TRL 6).

\subsubsection{Phase C/D: Flight System Development} In this phase, the practicability of the design will be studied and validated using a full-scale system. The goal of this phase is to demonstrate the performance of the full-scale prototype in a space-like environment and to flight-qualify the proposed system (TRL 7 - 9)

\subsection{Reducing Technology Development Cost}

The total development cost of the new proposed surface balloon inflation technology could be reduced if the technology development is done through corporation with U.S. universities. This is because university facilities and labors are generally less expensive compared to NASA and industry. A strategic partnership with University and NASA could also have a positive effect in aerospace community. The strategic university partnership will be able to involve undergraduate and graduate students into research activities inspiring new generation of space scientist and engineers. The opportunities will also provide participating students a handson experience during their college career preparing them for NASA and industry career. Consequently, students will mature faster as professionals to make contributions back to NASA and industry corporations which all benefits the aerospace community.

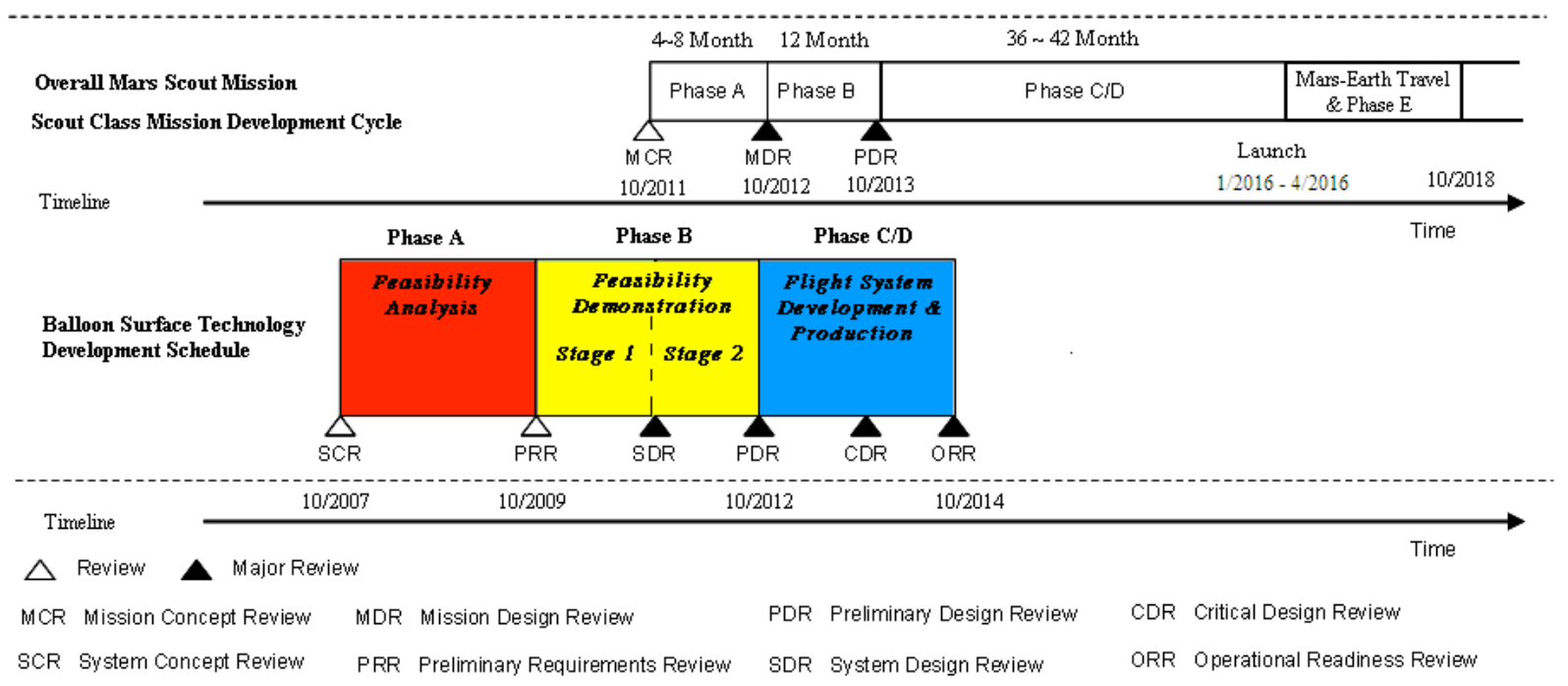

Figure 8-1: Technology Development Plan and Schedule 


\subsection{Preliminary Risk Analysis}

The preliminary risk analysis was performed to compare the conventional balloon deployment strategy and the new proposed surface deployment strategy. The risk analysis charts shown in this section is used to minimize the possibility of potential problem arising throughout the technology development of two balloon inflation systems concept. Following three key issues are implemented in the preliminary risk chart: technical, schedule, and cost.

\section{Technical}
A. Balloon Rupture due to aerodynamic loads.
B. Envelope material does not meet stress requirements.
C. Not being able control balloon inflation process due to environment.
D. Balloon does not fully inflate.

\section{Schedule}

E. Balloon Technology does not meet minimum TRL of 7 required for flight project by 2016 launch

Note: 2016 (or 2018) is the next realistic launch window for balloon mission to Mars [12]. (Predicted Technology cutoff deadline 2013)

\section{Cost}

F. Development Cost needed to mature technology exceeds allocated budget resulting delay in technology development.

\subsection{Conventional Aerial Balloon Deployment}

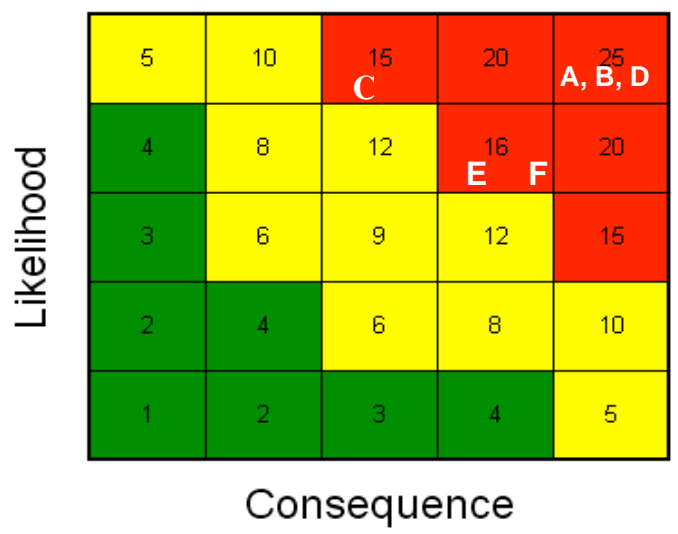

Figure 9-1: Risks Associated with the Conventional Aerial Balloon Deployment

\subsection{The Surface Balloon Deployment}

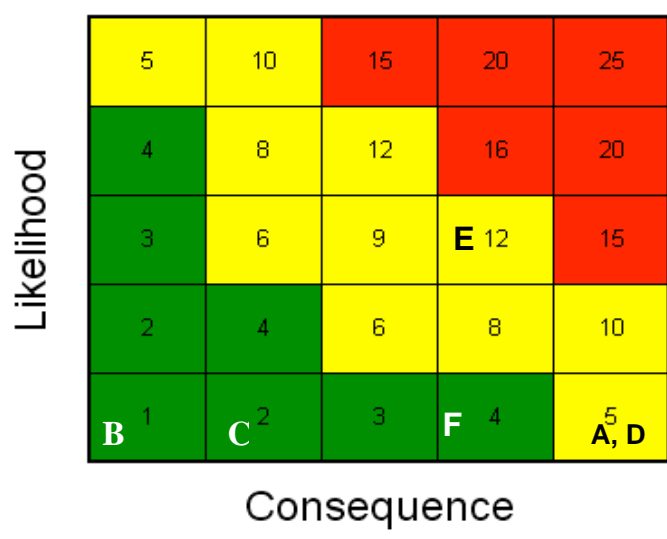

Figure 9-2: Risks Associated with the New Proposed Surface Balloon Deployment

\subsection{Risk Comparison Analysis Result}

From our preliminary risk analysis, the new surface balloon inflation system makes a compelling case for future Mars Balloon deployment strategy. The economical testing strategy allows the technology a chance of reaching the minimum TRL of 7 within allocated budget. Detailed explanations on how these risk items were analyzed and categorized are shown in Appendix E. 


\subsection{Education and Public Outreach}

The University of Michigan Mars Balloon Team members have been participating in a variety of Education and Public Outreach activities. The team has made significant contributions to further the interest of students of various age groups in space science and engineering. The Cherilyn Morrow EPO Diagram shown below summarizes our outreach activities.

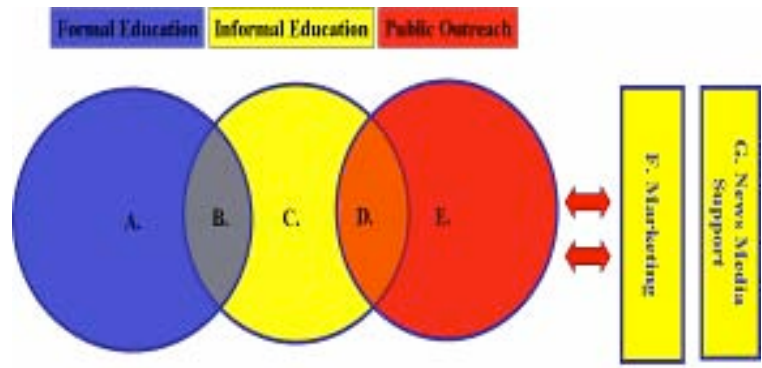

H. Supporting Local Business Owners

A. Cameron Balloon Guest Lecture in the Capstone Multidisciplinary Engineering Design Course.

B. University of Michigan 2007 Design Expo

B. 5th Annual K-grams Kids Fair

C. "Feel the Solar" Exhibit Design

D. Video Documentary

E. Project Website

F. Help Distributing NASA Mission posters and stickers

F. Ann Arbor Hands on Museum Outreach

G. "Feel the Solar" Exhibit Ground Opening

G. Channel 4 Interest

G. Presented in Ann Arbor Newspaper

H. Supporting Local Business Owners

Figure 10-1: EPO Diagram by Cherilyn Morrow

\subsection{Outreach Efforts to the General Public}

\subsubsection{Exhibit Design and Development}

The University of Michigan Mars Balloon Team has partnered with the local science museum, The Ann Arbor Hands-On Museum, to design and develop a new space science exhibit, Feel the Solar System, to inspire the public to gain interest in space science and engineering.

Feel the Solar System is an interactive children's exhibit that will allow visitors at the Ann Arbor Hands-On Museum to experience the gravitational pull of the Sun and the eight planets of the solar system. Our exhibit includes cylindrical representations of the Sun and planets mounted to a table top. The graphics of the interactive display were designed by artist Allan C. Edwards to match the true appearance of each planet and the Sun. The key components of our exhibit are magnets, a durable surface, cylindrical Sun and planet models, and visual aids. The exhibit coheres with the vision of the upcoming permanent space exploration exhibit floor at the Ann Arbor Hands-On Museum. Our exhibit effectively reflects the three learning characteristics-physical, cognitive and affective.

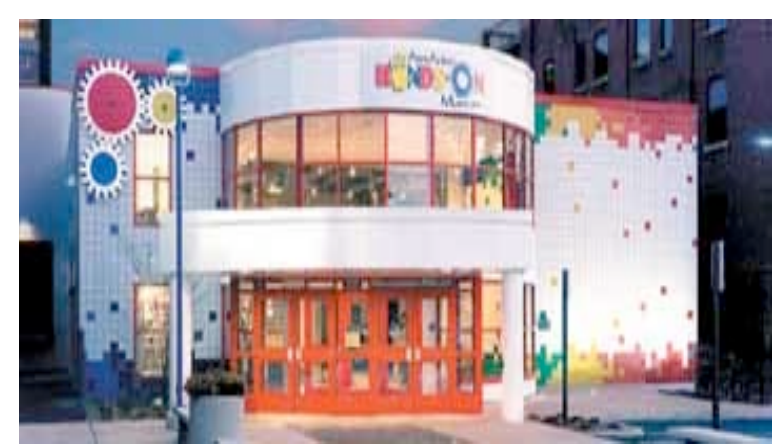

Figure 10-2: Ann Arbor Hands-On Museum Located in Ann Arbor, Michigan

\subsubsection{Exhibit Prototype Assessment}

In our formative evaluation, we developed a suite of assessment tools to evaluate the overall project design. A series of surveys were conducted as part of the evaluation process. The Mars Balloon team investigated the target audience's preconceptions, attitudes and levels of knowledge about the solar system to ultimately assist in the development of appropriate content that would adhere to the Ann Arbor Hands-On Museum. The overall formative evaluation deliverables answered the following questions:

- Did visitors interact with the exhibit?

- How effective were the exhibit cues? (verbiage)

- How well did visitors understand the exhibit message? (varying gravitational forces)

- How did visitors interpret the relevance of the exhibit? 


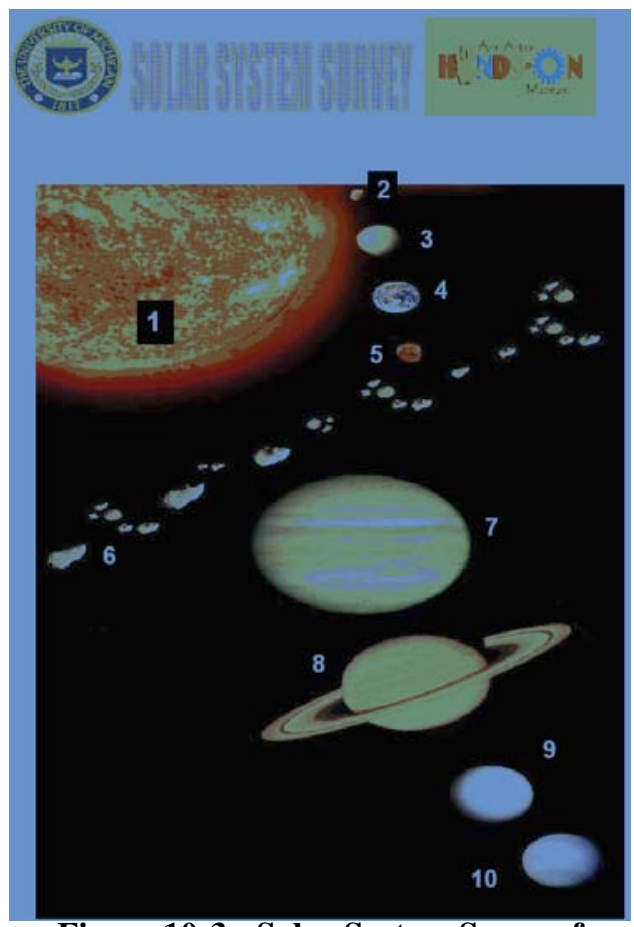

Figure 10-3: Solar System Survey for visit at Ann Arbor Hands-On Museum

First, we assessed cognitive elements of the Ann Arbor Hands-On Museum's design requirements by surveying parents and children on their knowledge about the solar system. Our target audience ranges from kindergarten through eighth grade. The National Science Education Standards and Benchmarks of Learning literature served as the baseline of knowledge expectation for students of grade levels kindergarten through eighth nationwide. In this evaluation, we wanted to acquire the level of understanding of the solar system and physics concepts relating to gravity. Multiple choice questions and two open-ended questions were chosen to determine if the visitor could recognize any of the objects using only visual aids in the appropriate content level for verbiage on the exhibit.

Survey results indicated that the children were more knowledgeable about the solar system than their parents. Furthermore, children recognized that Pluto was not a planet and that it was not labeled in the corresponding viewgraph of the solar system. All visitors demonstrated a strong interest in learning more about the solar system.

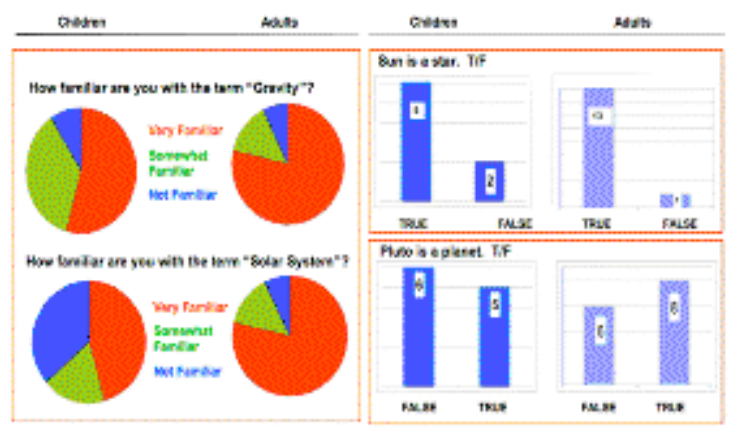

Figure 10-5: Pre-Evaluation Results

Our team tested the affective aspect of the exhibit allowing users to attempt to feel the difference of gravitational force on the Sun and each planet. The evaluations were conducted at the University of Michigan Design Expo event and in a college classroom.

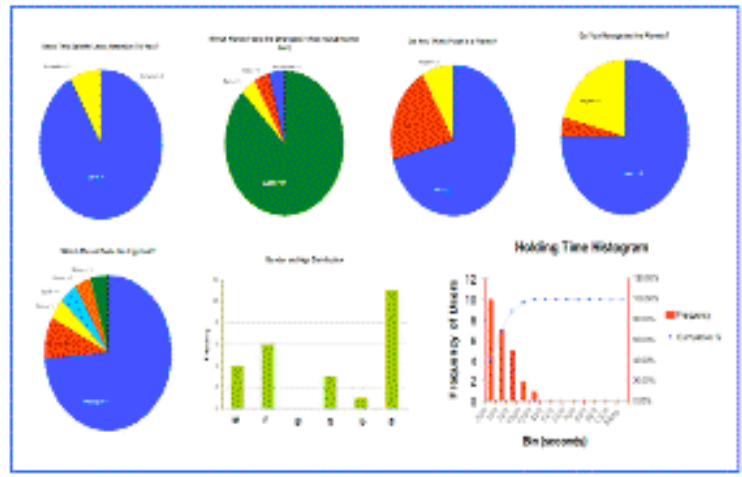

Figure 10-6: Post-Evaluation Results

During our opening day, we conducted postevaluation surveys to assess whether our final prototype design was successful.

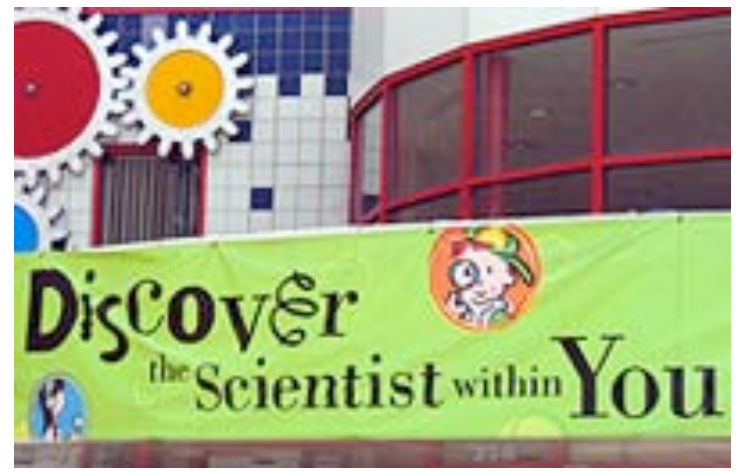

Figure 10-4: The Mission of the Ann Arbor Hands-On Museum is to Inspire People to Discover the Wonder of Science, Math, and Technology 


\subsubsection{Exhibit Display Grand Opening}

On May 12th of 2007, our team opened our exhibit, Feel the Solar System, at the Ann Arbor Hands-On Museum.

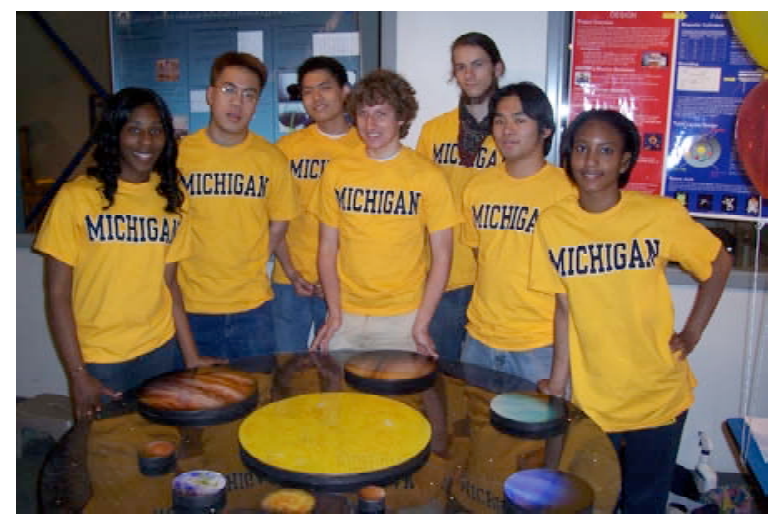

Figure 10-7: Mars Balloon Team at 'Feel the Solar System' Grand Opening

On the opening day, we distributed educational material provided by Linda Butler from New Horizons' Education and Public Outreach division. The material provides general information about the solar system and the New Horizon's mission. In addition, Carla Bitter, Education and Public Outreach Manager of the Phoenix Mars Scout Mission, provided educational material to be handed out to the general public. This material describes the concept of comparative planetology and the upcoming Phoenix mission.

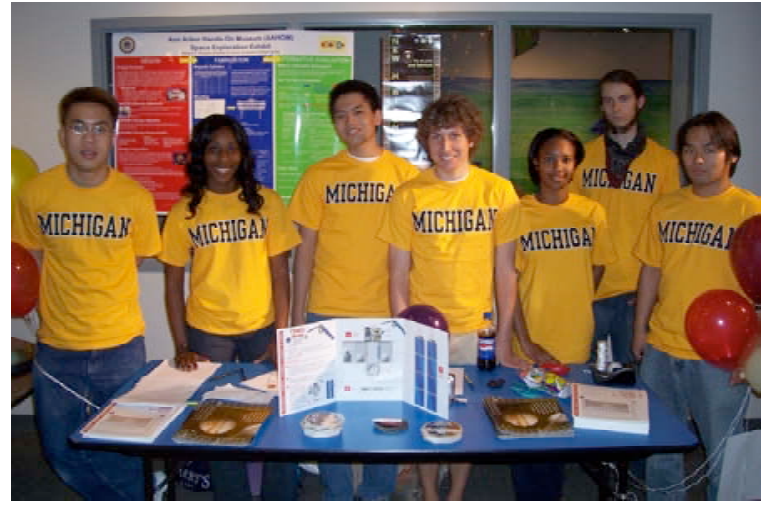

Figure 10-8: Mars Balloon Team Supporting NASA EPO Activities prototype space exhibit met our customer expectations.

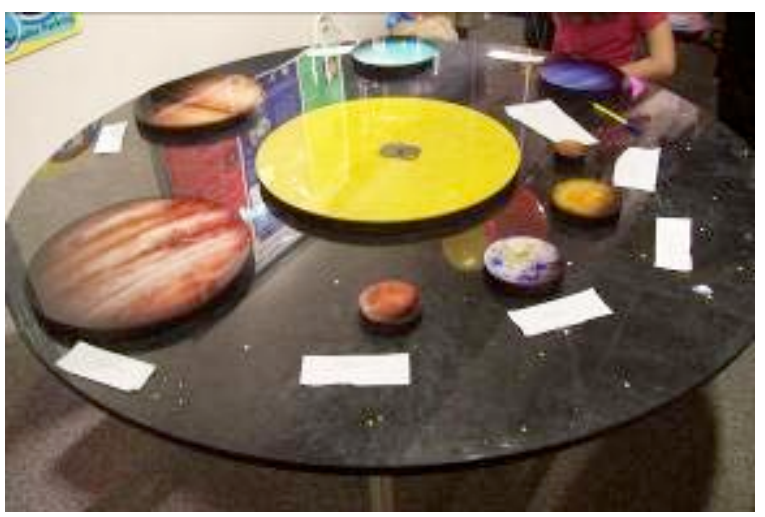

Figure 10-4: "Feel the Solar System" View

\subsection{Outreach Efforts to Elementary School}

The University of Michigan Mars Balloon team also participated in the 5th annual K-Grams (Kids Program) Kid Fair, which took place on March 13, 2007 in Ann Arbor, MI. Over one thousand elementary school children from the Detroit area were brought to the Crisler Arena, where student groups entertained them while informing them about their groups. The University of Michigan Mars Balloon team inflated a large weather balloon and connected it to a webcam so the students could see themselves in our computer as they walked by. We also had them draw pictures of space ships that could go to Mars. As they drew, we informed them of the purpose of our group and NASA's vision of exploration of the Moon and eventually to Mars.

\subsection{Outreach Efforts at the University}

We presented our project at the annual University of Michigan Design Expo on April 12, 2007. Our team displayed both a poster and a PowerPoint presentation. Many students, faculty, staff and local residents attend this event. We explained the objectives of our new Mars balloon concept to the public.

Our group brought posters and helium balloons to the Ann Arbor Hands-On Museum for a funfilled day. Meanwhile, formative evaluation assessments were conducted to ensure that our 


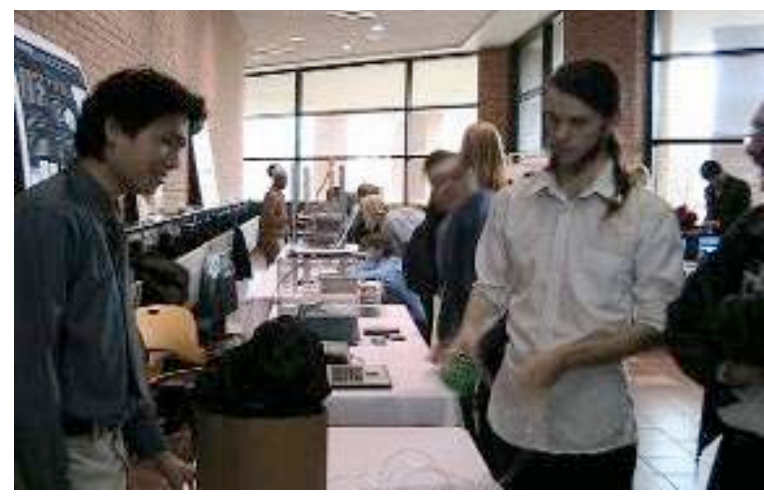

Figure 10-5: Mars Balloon Project Presentation at Design Expo - Ann Arbor, MI

We also used the opportunity to display our exhibit design Feel the Solar System to college students. We explained why the Feel the Solar System project was important and how it would help children of all ages to better understand concepts related to our solar system.

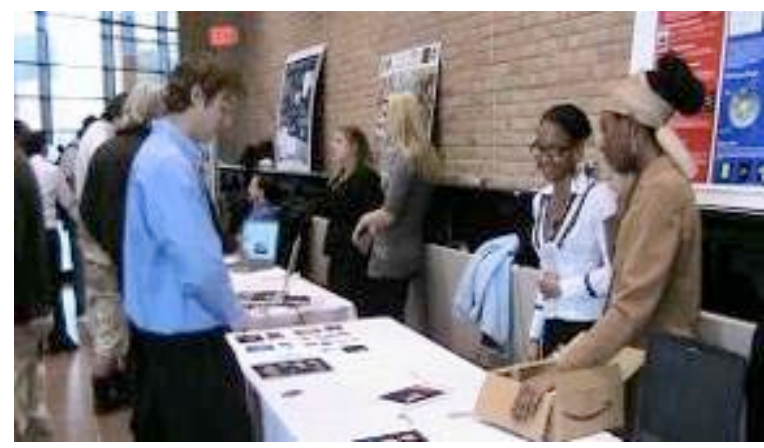

Figure 10-6: "Feel Solar System" Science Exhibit Displayed at Design Expo - Ann Arbor, MI

Our exhibit design was highlighted in the "Ann Arbor News" newspaper. Our group was also invited to talk about our project at the Channel 4 News station.

\subsection{Supporting Local Business}

The University of Michigan Mars Balloon Team supported small business owners in our community. Almost all of the parts for our prototypes were purchased at local businesses near the University of Michigan campus. We have also developed a strong relationship with a local balloon company, Cameron Balloon US, to help spread the joy of ballooning in our community.

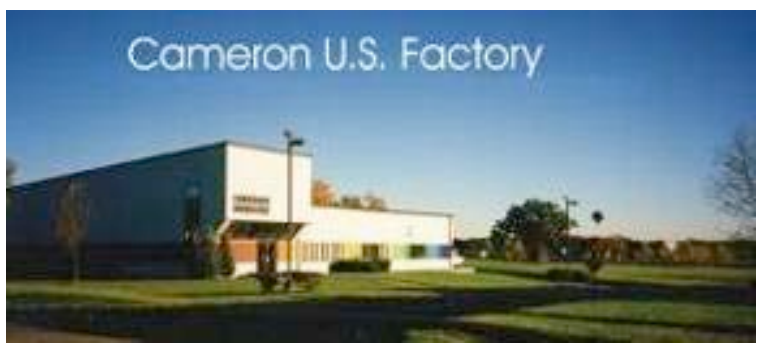

Figure 10-7: Cameron Balloons US

(Courtesy of Cameron Balloons US)

\subsection{Other Outreach Efforts}

The University of Michigan Mars Balloon Team created a website to publicize the new Mars surface balloon inflation concept. The website can be easily accessed by anyone-allowing interested students, researchers and the general public to access our project. We also created a documentary DVD of our balloon project that we plan to use to inspire high school and college students to work on multidisciplinary engineering design projects.

\subsection{Outreach Efforts at NASA Sponsored Education Program (RASC-AL Forum)}

The University of Michigan Mars Balloon Team sent six students to 5th Annual Revolutionary Aerospace Systems Concept - Academic Linkage forum, a student design competition sponsored by NASA-Langley Research Center (LRC) and University Space Research Association (USRA).

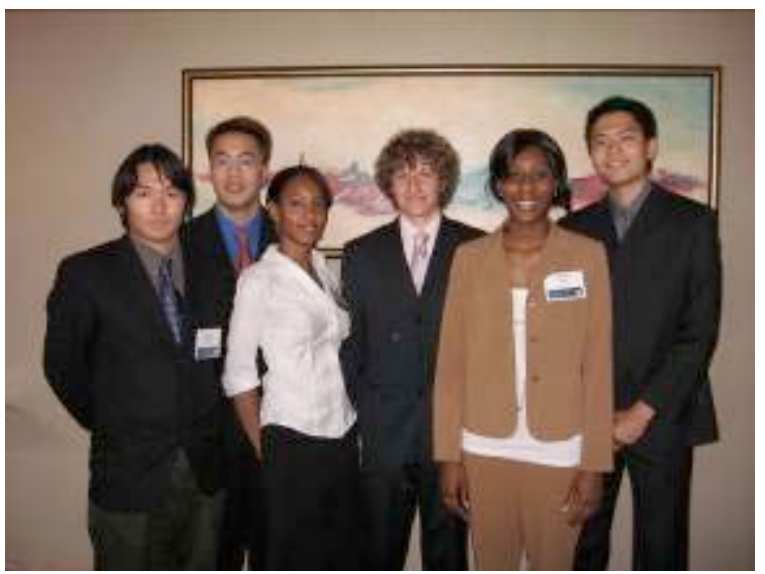

Figure 10-8: Mars Balloon Team at 2007 RASCAL Forum in Houston, Texas 
At the 2007 RASC-AL competition, the team felt compelled to show all attending guests the joy of ballooning by providing them the opportunity to make their own balloon. In addition, the team also toted the exhibit piece, "Feel the Solar System" to the competition where guests were able to "feel" the exhibit. The team's successful endeavor was documented and added it to the Mars balloon project documentary DVD. This documentary will be showcased to a capstone multidisciplinary engineering design courses at the University of Michigan and we will continue to add to it as future outreach opportunities arise.

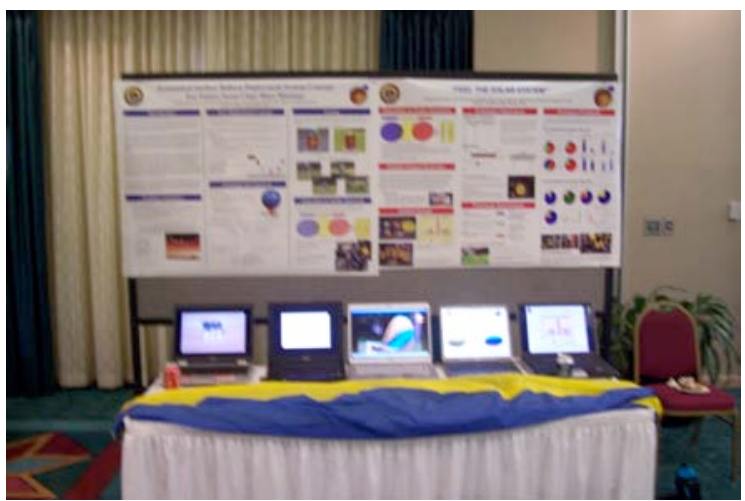

Figure 10-9: 2007 RASC-AL Poster Session

The UM Mars Balloon Team received a prestigious RASC-AL 2007 program recognition award for winning first place for their 'Economical Surface Inflation Concept for Future Mars Scout Class Mission'. The RASCAL Forum took place in Houston, Texas during week of May 21-24th, 2007.

\section{Acknowledgements}

The University of Michigan Mars Balloon Team would like to thank, 2007 RASC-AL Forum Sterling Committee members, Daniel Boice, Adam Bruckner, Jeffery A. Cardenas, Peggy Evanich, Dean Fontenot, Michael McGee, Carrie D. Olsen, Lewis Peach, Catherine Pieronek, Dale Rogers along with NASALangley Research Center and University Space Research Association for supporting student education including hosting of the 2007 RASCAL Forum and travel assistance for students to participate in the forum and AIAA conference. We would also like to sincerely thank Stephen
Mackwell, Karin Hilser, Elizabeth Wagganer, and Ben Houser from University Space Research Association for their contribution in 2007 RASC-AL Forum and for supporting student teams. We would also like to thank the University of Michigan, College of Engineering, and Department of Atmospheric, Oceanic, and Space Science for supporting space science, and engineering research activities for students for supporting our activities.

\section{References}

[1] G.W. Bush, "President Bush Delivers Remarks On U.S. Space Policy", NASA Facts, 14 January 2007

[2] J.L. Hall, M.T. Pauken, V.V. Kerzhanovich, G.J. Walsh, D. Fairbrother, C. Shreves, and T. Lachenmeier, "Flight Test Results for Aerially Deployed Mars Balloons", AIAA Balloon Systems Conference, Williamsburg, VA, 21-24 May 2007, AIAA 2007-2626.

[3] V.V. Kerzhanovich, J. Cutts, H. Cooper, J. Hall, B. McDonald, M. Pauken, C. White, A. Yavrouin, A. Castano, H. Cathey, D. Fairbrother, S. Smith, C. Shreves, T. Lachenmeier, E. Rainwater, and M. Smith, "Breakkthrough in Mars Balloon Technology", COSPAR Balloon Technology Conference, 2002.

[4] V.V. Kerzhanovich, J. Cutts, A. Bachelder, J. Cameron, J. Hall, J Patzold, M. Quadrelli, A Yavrouian, J. Cantrell, T. Lachenmeire, and M. Smith, "Mars Aerobot Validation Program", AIAA Balloon Technology Conference, 1999, AIAA 99-3853.

[5] I.S. Smith, Jr., W.D. Perry, and T.M. Lew, "A Mars 2011 Balloon Mission Study: Assumptions, Science Drivers, Modeling and Results", AIAA Balloon Systems Conference, Williamsburg, VA, 21-24 May 2007, AIAA 2007-2624.

[6] K.T. Nock, J. Balaram, M.K. Heun, I.S. Smith, T Gamber, "Mars 2001 Aerobot/Balloon System Overview", AIAA A97-31331, 1997

[7] J. Umland, "Cruise, Entry, Descent, and Landing (CEDL)", 27 January 2005

[8] R.Z. Sagdeev, V.M. Linkin, E. Blamont, and R.A. Preston, "The Vega Venus Balloon Experiment", JSTOR, 21 March 1986.

[9] M.Israel, S. Boggs, M. Cherry, M. Devlin, H. Ford, J Grindlay, J. Margitan, J. Ormes, C. Raymond, D. Rust, E. Seo, and V. Jones, "NASA Stratospheric Balloons, Pioneers of Space Exploration and Research, Report of the Scientific Ballooning Planning Team”, NASA, October 2005.

[10] D. Crisp, "In-Situ Environmental Measurements for Mars Long-Lived Network", Jet Propulsion Laboratory, 16 February, 2003

[11] D. Crisp, C. LaBaw, C. Mahoney, O. Serviss, A. Harri, J. Polkko, S. Calcutt,J. Tillman, S. Larsen, and R. Haberle, "Netlander Atmis Wind and Temperature Instruments (ATMISWT)", Mars Netlander Discovery Project, April 2003 
[12] D.J. Mcleese, "Robotic Mars Exploration Strategy 2007

Appendix A: Small Balloon Concept Calculation

\section{Assumptions}

\begin{tabular}{lccc}
\hline Parameter & Symbol & Value & Units \\
\hline Mars Atmospheric Density (at Martian Surface) & $\rho$ & 0.015 & $\mathrm{~kg} / \mathrm{m}^{3}$ \\
Helium Gas Density (at Martian Surface) & $\rho_{\text {Helium }}$ & 0.00139 & $\mathrm{~kg} / \mathrm{m}^{3}$ \\
Diameter of Spherical Supperpressure Balloon & $\mathrm{D}$ & 20.0 & $\mathrm{~m}$ \\
Mars Balloon Envelope Material Surface Density & $\rho_{\mathrm{s}}$ & 0.010 & $\mathrm{~kg} / \mathrm{m}^{2}$ \\
\hline
\end{tabular}

The lifting ability of the balloon per square meter can be approximate by difference in gas density, $\Delta \rho$.

$$
\begin{gathered}
\Delta \rho=\rho-\rho_{\text {Helium }} \\
\Delta \rho=0.015 \mathrm{~kg} / \mathrm{m}^{3}-0.00139 \mathrm{~kg} / \mathrm{m}^{3}=0.0136 \mathrm{~kg} / \mathrm{m}^{3}
\end{gathered}
$$

Mass of the balloon envelope can be calculated with below equation using above Assumptions.

$$
\begin{gathered}
M_{\text {Balloon_Envelope }}=4 * P I *(D / 2)^{2} * \rho_{S} \\
M_{\text {Balloon_Envelope }}=4 * P I *(20 \mathrm{~m} / 2)^{2} * 0.010 \mathrm{~kg} / \mathrm{m}^{2}=12.5 \mathrm{~kg}
\end{gathered}
$$

Calculation shown below will be able to determine the minium diameter needed for the small balloon.

$$
\begin{gathered}
\text { Lift_Power }(\mathrm{kg})=4 / 3 *\left(D_{\text {Small }} / 2\right)^{3} * \Delta \rho \\
\text { Lift_Power }(\mathrm{kg})=M_{\text {Small_Envelope }_{-}}+M_{\text {Balloon_Envelope }} \\
\text { (To be Nautually Buoyant) }
\end{gathered}
$$

$$
\begin{gathered}
\text { Lift_Power }(\mathrm{kg})=4 / 3 *\left(D_{\text {Small }} / 2\right)^{3} * \Delta \rho=M_{\text {Small_Envelope }}+M_{\text {Balloon_Envelope }} \\
M_{\text {Small_Envelope }}=4 * P I *\left(D_{\text {Small }} / 2\right)^{2} * \rho_{S} \\
4 / 3 *\left(D_{\text {Small }} / 2\right)^{3} * \Delta \rho=4 * P I *\left(D_{\text {Small }} / 2\right)^{2}+M_{\text {Balloon_Envelope }} \\
4 / 3 *\left(D_{\text {Small }} / 2\right)^{3} * 0.0136 \mathrm{~kg} / \mathrm{m}^{3}=4 * P I *\left(D_{\text {Small }} / 2\right)^{2}+12.5 \mathrm{~kg}
\end{gathered}
$$

Solve for Diameter of Small Balloon (1 Equation, 1 Uknown)

$$
\begin{gathered}
D_{\text {small }}=13.7 \text { meter } \\
D_{\text {small }} / \mathrm{D}=0.675
\end{gathered}
$$

Reference Table:

\begin{tabular}{|l|cccc|}
\hline Balloon Envelope Surface Density & $0.005 \mathrm{~kg} / \mathrm{m}^{2}$ & $0.010 \mathrm{~kg} / \mathrm{m}^{2}$ & $0.015 \mathrm{~kg} / \mathrm{m}^{2}$ & $0.020 \mathrm{~kg} / \mathrm{m}^{2}$ \\
Diamter of Small Balloon & $50 \%$ & $67.5 \%$ & $82.0 \%$ & $94 \%$ \\
\hline
\end{tabular}




\section{Appendix B: Scaling Parameter Derivation}

\section{B-1: Aero-Kinetic Parameter Derivation}

We will establish the validity of $U^{2} / D$ as the "natural acceleration of vortices around a body" where body includes a balloon envelope. We will then establish Rho* $\mathrm{U}^{2} / \mathrm{Rho} S \mathrm{~S}$ as the "natural acceleration of a balloon envelope in the wind" and call our Aero-Kinetic Parameter the ratio of the two numbers, which simplifies to Rho*D/Rho_S.

We have a certain Reynolds number, and therefore a certain Stroul number $(f * D / U$; where $f$ is the frequency with which vortices are shed from the surface of an object of diameter D within a fluid-flow of velocity $U$ ) this later number is essentially the dimensionless frequency of vortex movement over and behind the surface, and since it is determined, $\mathrm{f}$ is proportional to U/D. Multiplying both sides of this proportionality by the flow velocity shows that $f^{*} U$ is proportional to $U^{2} / D$; this we can call the dimensionless acceleration, and we can know it is about as certain as the Stroul number for a given Reynolds number. The graph bellow shows the level of determinism between these two numbers $(\operatorname{Re} \&$ $\mathrm{St}$ ), when the object is a cylinder within the fluid-flow:

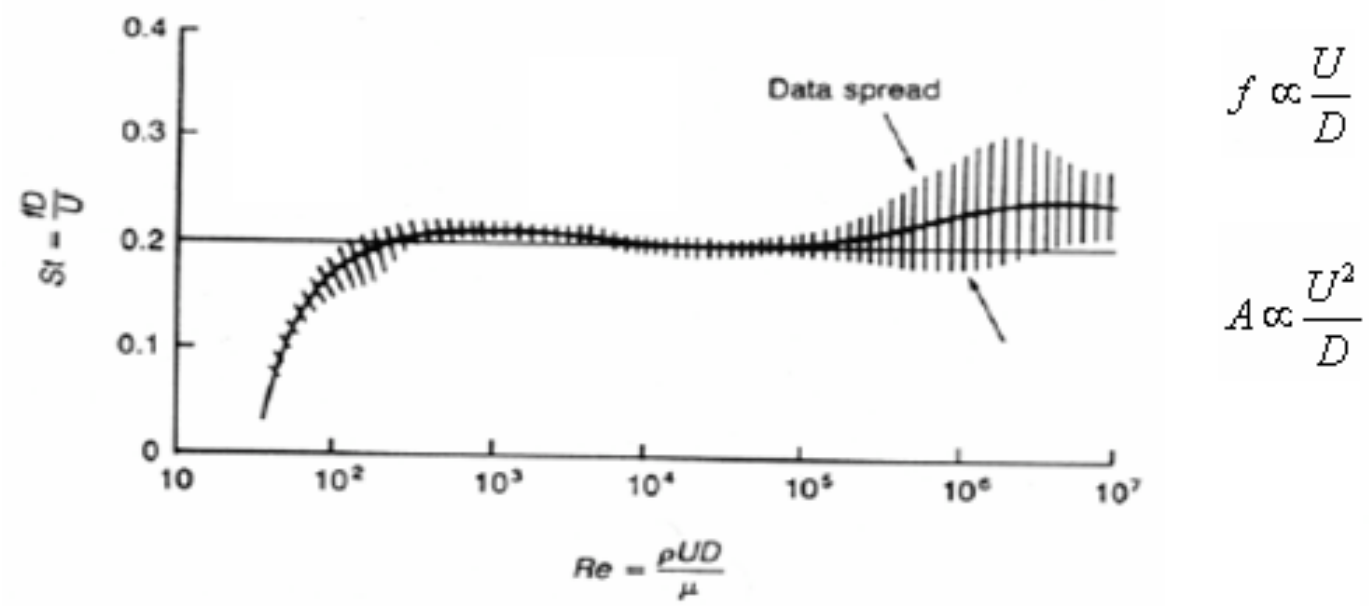

Figure B-1: Vortex Shedding Frequency around a Cylinder

As shown above in Figure B-1, the relationship is highly deterministic, in the case of a cylinder, over the Reynolds numbers we're interested in for the Mars balloon. Note: Assumptions, $\operatorname{Re} \sim 10^{\wedge} 5,20$ meter diameter balloon, and Wind Velocity $5 \mathrm{~m} / \mathrm{s}$ ).

All that remains is to compare this to the natural envelope surface element acceleration, which is taken from Newton's second law as shown below. 


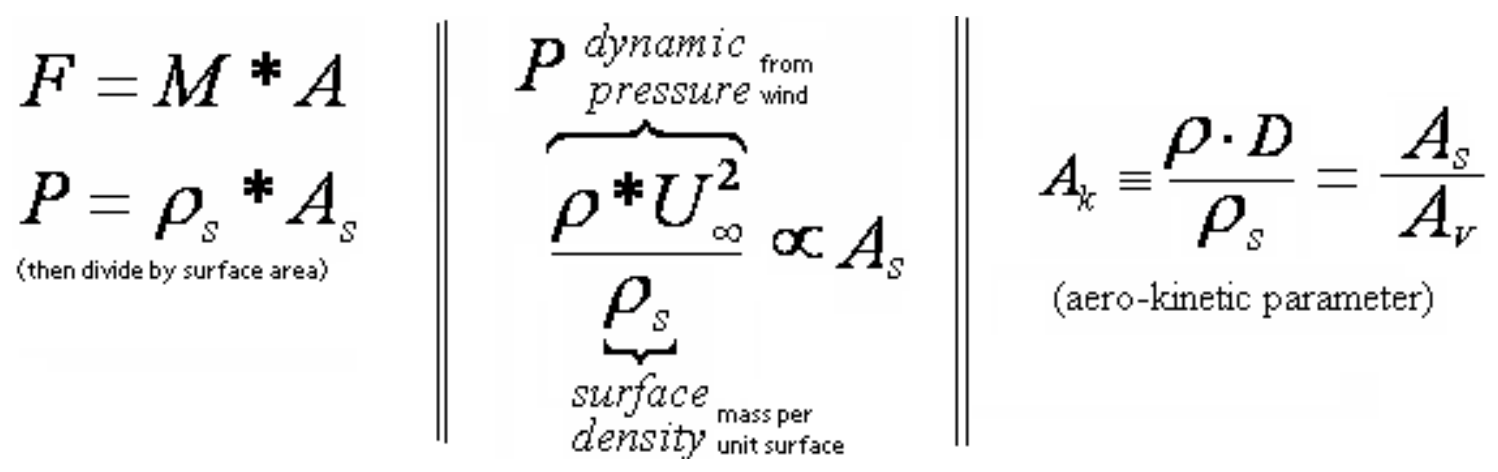




\section{Appendix B: Scaling Parameter Derivation}

\section{B-2: Envelope Stiffness Parameter Derivation}

Beam Theory:
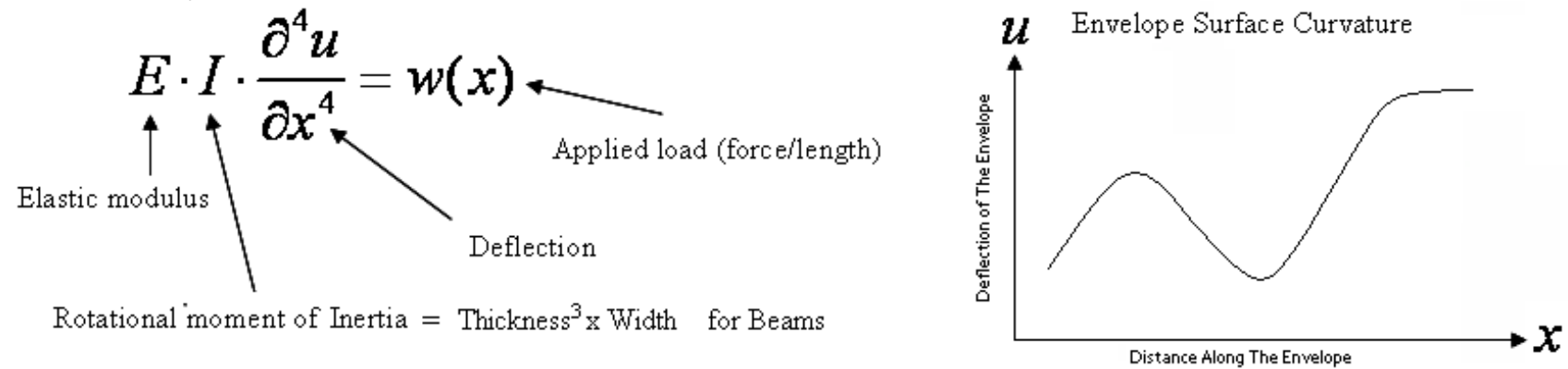

Now divide to make it independent of beam (envelope) width:

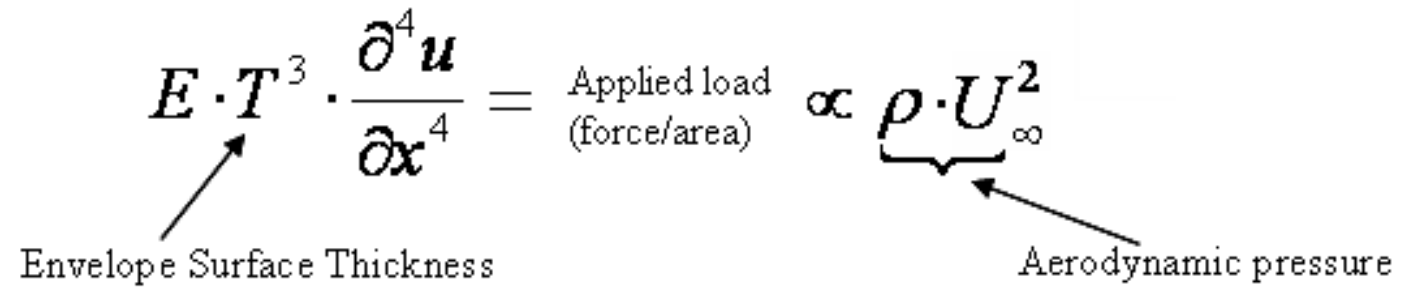

Notice that the above proportionality, as well as those below, are dependant on the geometric similarity of full-size and scale models. If we can say that this geometric similarity will be created, in part, by ensuring the proportionality, then the envelope stiffness parameter $(\mathrm{Su})$ has been properly defined.

$$
\begin{array}{c|c}
u \propto x \propto D & \frac{\partial^{4} u}{\partial x^{4}} \propto \frac{1}{D^{3}} \\
\frac{E \cdot T^{3}}{D^{3}} \propto \rho \cdot v^{2} & S u \equiv \frac{E \cdot T^{3}}{D^{3} \cdot \rho \cdot U_{\infty}^{2}}
\end{array}
$$




\section{Appendix C: Non-Dimensional Number Matching to Determine of Scaling Ratios}

\section{C-1: Formulation:}

Given five non-dimensional numbers, we needed experimental scaling factors to make all nondimensional numbers the same on Earth and Mars. Our approach is demonstrated using the buoyancy number 'Bu' as an example.

$$
B u=\frac{\Delta \rho * D}{\rho_{s}}
$$

Let subscript ' $M$ ' denote physical values on Mars and let subscript ' $E$ ' denote values on Earth. We want to match non-dimensional numbers, thus let

$$
\begin{gathered}
B u_{E}=B u_{M} \\
\frac{B u_{E}}{B u_{M}}=1
\end{gathered}
$$

Let the subscript ' $R$ ' denote the ratio of a physical variable on Earth to the same variable on Mars. When $B u$ is expressed as the ratio of physical quantities on Earth to the same values on Mars, the result is

$$
B u_{R}=\frac{\frac{\Delta \rho_{E}}{\Delta \rho_{M}} * \frac{D_{E}}{D_{M}}}{\frac{\rho_{s_{-}}}{\rho_{s_{-} M}}}=\frac{\Delta \rho_{R} * D_{R}}{\rho_{s_{-} R}}=1
$$

The same process applies to the other non-dimensional numbers, so we have a set of five simultaneous equations, shown below.

$$
\begin{gathered}
R e_{R}=\frac{v_{R} * \rho_{R} * D_{R}}{\mu_{R}}=1 \\
F r_{R}=\frac{\rho_{R} * v_{R}^{2}}{\Delta \rho_{R} * g_{R} * D_{R}}=1 \\
A k_{R}=\frac{\rho_{R} * D_{R}}{\rho_{s_{-} R}}=1 \\
B u_{R}=\frac{\Delta \rho_{R} * D_{R}}{\rho_{s_{-}}}=1 \\
T s_{R}=\frac{\rho_{R} * v_{R}^{2} * D_{R}}{\tau_{R}}=1
\end{gathered}
$$

These are five equations with eight unknowns. However, three of these unknowns ( $\rho$ - atmospheric density, $g$ - gravitational acceleration, $\mu$ - wind viscosity) are nearly constants for this given experiment, assuming that the non-dimensional numbers must only be matched on the ground. 


\section{Appendix C: Non-Dimensional Number Matching to Determine of Scaling Ratios}

\section{C-2: Known Quantities}

The atmospheric density on the Mars surface, $\rho_{M}$, is assumed to be $0.015 \mathrm{~kg} / \mathrm{m}^{3}$ when $\mathrm{T}=-32 \mathrm{C}$

The atmospheric density on the Earth surface, $\rho_{E}$, is assumed to be $1.20 \mathrm{~kg} / \mathrm{m}^{3}$ when $\mathrm{T}=20 \mathrm{C}$ Thus, the ratio of the atmospheric density on Mars and Earth is:

$$
\rho_{R}=79.42
$$

Gravitational accelerations of Mars and Earth at their surfaces are $g_{M}=3.69 \frac{\mathrm{m}}{\mathrm{s}^{2}}$ and $g_{E}=9.78 \frac{\mathrm{m}}{\mathrm{s}^{2}}$.

Thus, the ratio of the gravitational accelerations is:

$$
g_{R}=2.65
$$

Viscosity of air on Earth, $\mu_{E}$, is assumed to be $1.84 \times 10^{5} \mathrm{~kg} / \mathrm{m} / \mathrm{s}$ when $\mathrm{T}=20 \mathrm{C}$.

Viscosity of air on Mars, $\mu_{M}$, is assumed as $\mathrm{CO}_{2}$ gas at $\mathrm{T}=-32 \mathrm{C}$ which has viscosity of $1.22 \times 10^{5}$ $\mathrm{kg} / \mathrm{m} / \mathrm{s}$ (Mars Atmosphere is composed of $95 \%$ Carbon Dioxide)

Thus, the ratio of the viscosity of air is:

$$
\mu_{R}=1.51
$$

\section{C-3: Known Quantities}

Knowing these three ratios, we can solve for five unknowns in five equations in a solver. The result is shown below.

$$
\begin{aligned}
D_{R}= & 0.05148 \\
\sim & 0.05 \\
\Delta \rho_{R} & =79.42 \\
& \sim 80 \\
\rho_{s_{-} R} & =4.088 \\
& \sim 4 \\
\tau_{R} & =0.5577 \\
\sim & 0.55 \\
v_{R} & =0.3693 \\
\sim & 0.37
\end{aligned}
$$




\section{Appendix D: Height Requirement Analysis}

\section{D-1: Risk of Balloon Touching the Ground}

\section{Assumptions}

\begin{tabular}{lccc}
\hline Parameter & Symbol & Value & Units \\
\hline Mars Atmospheric Density (at Martian Surface) & $\rho_{\text {Mars }}$ & 0.015 & $\mathrm{~kg} / \mathrm{m}^{3}$ \\
Helium Gas Density (at Martian Surface) & $\rho_{\text {Helium }}$ & 0.00139 & $\mathrm{~kg} / \mathrm{m}^{3}$ \\
Mars Balloon Envelope Material Surface Density & $\rho_{\mathrm{s}}$ & 0.010 & $\mathrm{~kg} / \mathrm{m}^{2}$ \\
\hline
\end{tabular}

Note: $\mathrm{D}$ used in equations below is not representing a diameter of balloon. $\mathrm{D}$ is diameter of a spherical volume at the top of the balloon. We assume that the helium goes to the top of the balloon immediately, filling a spherical volume at the top of the balloon, while the un-inflated balloon material is deployed through the cylinder. The volume of the small sphere dictates the buoyant force on the top of the balloon, and the length of slack material determines the downward force on the top of the balloon.

$$
\begin{gathered}
M_{\text {Envelope_Mass }_{-}}=4 \pi\left(\mathrm{D} / \mathrm{C}^{2} \rho_{S}\right. \\
\text { Buoyancy }=4 / 3 \pi(\mathrm{D} / 2)^{3}\left(\rho_{\text {Mars }}-\rho_{\text {Helium }}\right)
\end{gathered}
$$

To be above neutrally buoyant below equation must be satisfied:

By Substitution

$$
\frac{M_{\text {Envelope_Mass }}}{\text { Buoyancy }} \leq 1
$$

$$
\frac{M_{\text {Envelope_Mass }}}{\text { Buoyancy }}=\frac{4 \pi(D / 2)^{2} \rho_{S}}{4 / 3 \pi(D / 2)^{3}\left(\rho_{\text {Mars }}-\rho_{\text {Helium }}\right)} \leq 1
$$

Simply

Solving this for D

$$
\frac{\rho_{s}}{1 / 3(D / 2)\left(\rho_{\text {Mars }}-\rho_{\text {Helium }}\right)} \leq 1
$$

$$
\begin{gathered}
D \geq \frac{6 \rho_{s}}{\left(\rho_{\text {Mars }}-\rho_{\text {Helium }}\right)} \\
D \geq \frac{6 * 0.010 \mathrm{~kg} / \mathrm{m}^{2}}{\left(0.015 \mathrm{~kg} / \mathrm{m}^{2}-0.00139 \mathrm{~kg} / \mathrm{m}^{3}\right)} \\
\text { Height }=D \geq 4.4 \mathrm{~m}
\end{gathered}
$$

Reference Table:

\begin{tabular}{|l|cccc|}
\hline Balloon Envelope Surface Density & $0.005 \mathrm{~kg} / \mathrm{m}^{2}$ & $0.010 \mathrm{~kg} / \mathrm{m}^{2}$ & $0.015 \mathrm{~kg} / \mathrm{m}^{2}$ & $0.020 \mathrm{~kg} / \mathrm{m}^{2}$ \\
Height of Funnel Required & $2.2 \mathrm{~m}$ & $4.4 \mathrm{~m}$ & $6.6 \mathrm{~m}$ & $8.8 \mathrm{~m}$ \\
\hline
\end{tabular}




\section{Appendix D: Height Requirement Analysis}

\section{D-2: Risk of Gondola Touching the Ground}

\section{Assumptions}

\begin{tabular}{lccc}
\hline Parameter & Symbol & Value & Units \\
\hline Mars Atmospheric Density (at Martian Surface) & $\rho_{\text {Mars }}$ & 0.015 & $\mathrm{~kg} / \mathrm{m}^{3}$ \\
Diameter of Spherical Supperpressure Balloon & $\mathrm{D}$ & 20.0 & $\mathrm{~m}$ \\
Mars Balloon Envelope Material Surface Density & $\rho_{\mathrm{s}}$ & 0.010 & $\mathrm{~kg} / \mathrm{m}^{2}$ \\
Length of Tether (4.5 times of Balloon Diameter) & $\mathrm{L}$ & 90 & $\mathrm{~m}$ \\
Wind Velocity at Gondola Deployment & $\mathrm{V}_{\text {Wind }}$ & 5 & $\mathrm{~m} / \mathrm{s}$ \\
Assumed Lift Power of the Balloon System (with Payload) & $\mathrm{F}_{\mathrm{L}}$ & 70 & $\mathrm{~N}$ \\
Coefficient of Drag of Spherical Balloon & $\mathrm{C}_{\mathrm{D}}$ & 0.44 & \\
\hline
\end{tabular}

Newton's resistance equations can calculate the drag force generated by balloon with relative velocity. Assume balloon is pushed by a wind and does not generate thrust. In our case, it is assumed that relative velocity is same as wind velocity, $\mathrm{V}_{\text {Wind }}$.

$$
\begin{gathered}
F_{D}=1 / 8 * \pi * C_{D} * \rho_{\text {Mars }} * D^{2} * V^{2} \\
F_{D}=1 / 8 * \pi * 0.44 * 0.1015 \mathrm{~kg} / \mathrm{m}^{3} *(20 \mathrm{~m})^{2} *(5 \mathrm{~m} / \mathrm{s})^{2} \cong 26 N
\end{gathered}
$$

Note: In Newton's Law region, $1000<\operatorname{Re}<2 \times 10^{5}, C_{D}$ is about 0.44 . Re is about $1 \times 10^{5}$ on Mars.

$$
\begin{gathered}
F_{L} \cos (\theta)=F_{D} \sin (\theta) \\
F_{L} / F_{D}=\sin (\theta) / \cos (\theta)=\tan (\theta) \\
\theta=\tan ^{-1}\left(F_{L} / F_{D}\right) \\
\theta=\tan ^{-1}(70 N / 26 N)=70 \mathrm{deg}
\end{gathered}
$$

Determine the funnel height requirement due to gondola hitting the ground during deployment

$$
\begin{gathered}
H_{\text {Funnel }}=[L+(D / 2)]-[L+(D / 2)] \operatorname{in}(\theta) \\
\left.H_{\text {Funnel }}=(00 m+(20 m / 2)\rfloor-90 m+(20 m / 2)\right] \operatorname{in}(70 \mathrm{deg}) \cong 6.2 m \\
H_{\text {Funnel }} \cong 6.2 m
\end{gathered}
$$

Note: Shorter tether length can reduce the funnel height requirement or able to accommodate deployment with higher wind velocity. 


\section{Appendix E: Results of the Preliminary Risk Analysis}

\section{E-1: Conventional Aerial Balloon Deployment}

\begin{abstract}
A - Risk Score 25 (Maximum Risk Rating)
Both, likelihood and consequence is at highest. Balloon has the highest risk of experiencing rupture due to fast descent velocity. Consequence of this would be total mission failure.
\end{abstract}

\section{B - Risk Score 25 (Maximum Risk Rating)}

Both, likelihood and consequence is at highest. Balloon envelope material has high stress requirements due to fast descent velocity. The advancement in thin film technology is needed. Consequence of not meeting the requirements would result in total mission failure.

\section{C - Risk Score 15}

Likelihood is highest due to limited inflation time available for balloon deployment (Maximum 2-3 minutes during EDL). Lifting gas flow rate is at close to maximum thus, it is not possible to control the inflation depending on the environmental input. Assuming that technology is fully flight ready, it will still give significant amount of uncertainties in the system.

\section{D - Risk Score $2 \underline{5}$ (Maximum Risk Rating)}

Both, likelihood and consequence is highest. Many environmental conditions may effect the inflation resulting balloon to not fully inflate. Consequence of this would be total mission failure.

\section{E - Risk Score 16}

Both, Likelihood and consequence is in the red zone. Only a few stratospheric tests can be conducted each year and this technology can only mature by trial and error. Thus, there is a high risk of not enough tests/trials being conducted to mature this technology. Since, the deployment technology is the key for mission success, the risk is high.

\section{F - Risk Score $\underline{16}$}

Both, likelihood and consequence is in the red zone. Due to small funding allocation, the technology development has not progressed enough. The delay in technology development may imply that the technology cut off is not reached.

\section{E-2: New Proposed Surface Balloon Deployment}

\section{A - Risk Score 5}

Balloon will be deployed after landing thus, it will not experience aerodynamic loading that conventional system experience during descent phase. The only aerodynamic load which may cause to rupture the balloon would be in situation where gust winds blow the balloon to the ground and surface friction causes balloon to rupture. Consequence of the balloon rupture will result in unsuccessful balloon deployment. However, this risk can be mitigated with our deployable cylinder system concept.

\section{B - Risk Score 1}

The surface balloon inflation system can meet the envelope stress requirements because existing film materials meet this requirement.

\section{C - Risk Score 2}

It is in green zone. Inflation of the balloon is done after landing thus inflation can be done anytime without a deployment-time constraint. Various sensors including wind sensors onboard can be used to monitors the environmental conditions before starting the balloon deployment. These metrological data could be used to analyze wind pattern at the landing site, helping operators and scientists to decide when the most appropriate time to start inflation is therefore minimizing the risks.

\section{D - Risk Score 5}

The likelihood of the balloon not being inflated fully is low since surface balloon deployment can easily control the balloon inflation.

\section{E - Risk Score 12}

The risk is in yellow zone because the concept is new. Balloon development may experience delay because the current TRL is low. Unforeseen problems may arise during the development. Delays might cause the technology cutoff deadline to be missed.

\section{F- Risk Score 4}

The risk is in green zone because the costs of ground deployment tests are low. Most tests can be done on the ground in existing test facilities at NASA, Industry, and University laboratories. 